\title{
An operational model for the West Iberian coast: products and services
}

\author{
M. Mateus ${ }^{1}$, G. Riflet ${ }^{1}$, P. Chambel ${ }^{2}$, L. Fernandes ${ }^{1}$, R. Fernandes ${ }^{1}$, M. Juliano ${ }^{3}$, F. Campuzano ${ }^{1}$, H. de Pablo ${ }^{1}$, and \\ R. Neves ${ }^{1}$ \\ ${ }^{1}$ MARETEC, Instituto Superior Técnico, Universidade Técnica de Lisboa, Av. Rovisco Pais, 1049-001, Lisboa, Portugal \\ ${ }^{2}$ HIDROMOD, Rua Rui Teles Palhinha, $n^{\circ} 4,1^{\circ}$, Leião, 2740-278 Porto Salvo, Portugal \\ ${ }^{3}$ LAMTec, Laboratory of Marine Environment and Technology, University of the Azores, Praia da Vitória, Azores, Portugal
}

Correspondence to: M. Mateus (mmateus.maretec@ist.utl.pt)

Received: 28 February 2012 - Published in Ocean Sci. Discuss.: 12 April 2012

Revised: 6 August 2012 - Accepted: 6 August 2012 - Published: 31 August 2012

\begin{abstract}
This paper presents the structure and application of a regional scale operational modelling tool for the West Iberian coast, and discusses its potential for products and services for both scientific and coastal management activities. The forecasting suite includes nested hydrodynamic models forced with up-to-date meteorological forecast data and large-scale model results. The present status of the system and its recent upgrades are reviewed, offering a general description of the main components of the system: the forcing data, the circulation model, the model outputs and the validation methodology of model results. Seasonal differences in temperature, salinity and current velocity fields are illustrated and show satisfactory reproduction of the top and deep layer thermodynamics. The system provides boundary forcing for a number of local-scale model applications via downscaling of the solution and enables potential products and services from which civil society will benefit.
\end{abstract}

\section{Introduction}

The development of nowcasting and forecasting systems during the last decades is responsible for significant scientific and technical achievements related to operational oceanography (Le Traon et al., 2009). Numerical models have become irreplaceable tools to link operational oceanography to marine affairs because they continuously provide state estimates and forecasts of coastal ocean state. The importance of numerical modelling in operational activities is already established at scales ranging from the coastal (De Mey and
Proctor, 2009 and references included in this Special Issue) to the global ocean (Bell et al., 2009).

Over the last decades several operational modelling systems have been developed with different levels of complexity, objectives and end-users (Zhuang et al., 2011). Recent EU-funded projects such as the European COastal-shelf sea OPerational observing and forecasting system project (ECOOP), with participation of 72 institutions, highlight the relevance of operational systems for the ocean. Several operational platforms combining data gathering and modelling systems have been produced or upgraded in the progress of such projects (e.g. Zhuang et al., 2011; Stanev et al., 2011; Kordzadze and Demetrashvili, 2011; Korotaev et al., 2011).

The aim of operational forecast is to provide information that cannot be attained by other ways and to satisfy needs at different levels from the community, ranging from the private sector (e.g. oil industry) to public interests (e.g. water quality associated with public health). In this context, this paper addresses the potential contributions that an operational model for West Iberia may provide to the public and other end users.

This work has been mostly developed within the aim of project MyOcean, where the operational model MOHIDPCOMS (MOdelação HIDrodinâmica Portuguese Coast Operational Modeling System) is part of an intermediatelevel service, meaning that it depends on upstream largescale data/products (for model forcing, boundary conditions, validation, etc). In addition, it provides downstream services/products to local users. Particular attention is given to the potential role of the model in the context of marine resources, marine safety and in coastal and marine 
environments. MyOcean product Mediterranean Sea Ultra High Resolution Sea Surface Temperature Analysis was used to validate the MOHID-PCOMS. Argo floater data from IFREMER (French Research Institute for Exploration of the Sea) is also used for validation purposes.

The paper is arranged as follows: Section 2 describes the operational forecasting model scheme implementation. Some regional scale results are presented in Sect. 3, followed by the discussion of the relevance and major challenges of the system in Sect. 4. Section 5 gives a conclusion and an outlook on the work in progress and on future work.

\section{The implementation}

\subsection{The MOHID model}

The model used in this operational platform is the MOHID model (www.mohid.com). MOHID is a Portuguese acronym for MOdelação HIDrodinâmica. It is an open-source geophysical regional circulation model based at MARETEC, a research group at Instituto Superior Técnico (IST) in Portugal. MOHID is a free-surface, baroclinic model, which uses the hydrostatic and Boussinesq approximations and a rotating Cartesian reference frame with angular rotation rate $\vec{\Omega}$ following the seminal primitive ocean equations proposed by Bryan (1997). It solves the equations of advection-diffusion of temperature $T$, salinity $S$, and horizontal momentum $\rho u$ and $\rho v$, respectively expressed in Eqs. (1) to (3). It also solves the equation of continuity to determine the vertical velocity $w$ and the water elevation $\eta$ (Eq. (4)). The density $\rho$ is solved with the UNESCO state equation as a function of $S, T$ and pressure $p$ (Fofonoff and Millard, 1983). $\rho_{0}$ is a reference density of seawater near the surface.

$$
\begin{aligned}
& \frac{\partial}{\partial t} \int_{V} T d V+\oint_{A}(\overrightarrow{\boldsymbol{n}} \cdot \overrightarrow{\boldsymbol{v}}) T d S=\oint_{A}\left(\overrightarrow{\boldsymbol{n}} \cdot \overrightarrow{\boldsymbol{K}_{T} \boldsymbol{\nabla}}\right) T d S+S S_{T} .(1) \\
& \frac{\partial}{\partial t} \int_{V} S d V+\oint_{A}(\overrightarrow{\boldsymbol{n}} \cdot \overrightarrow{\boldsymbol{v}}) S d S=\oint_{A}\left(\overrightarrow{\boldsymbol{n}} \cdot \overrightarrow{\boldsymbol{K}_{S} \boldsymbol{\nabla}}\right) S d S+S S_{S} . \\
& \frac{\partial}{\partial t} \int_{V} \overrightarrow{\boldsymbol{v}} d V+\underbrace{\oint_{A}(\overrightarrow{\boldsymbol{n}} \cdot \overrightarrow{\boldsymbol{v}}) \overrightarrow{\boldsymbol{v}} d S}_{\text {Advection }}+\underbrace{\int_{V} 2 \overrightarrow{\boldsymbol{\Omega}} \times \overrightarrow{\boldsymbol{v}} d V}_{\text {Coriolis acceleration }} \\
& =\oint_{A}(\underbrace{\left(\overrightarrow{\boldsymbol{n}} \cdot \overrightarrow{\boldsymbol{v}_{T} \boldsymbol{\nabla}}\right) \overrightarrow{\boldsymbol{v}}}_{\text {Turbulent stress }}-\underbrace{g(\eta-z) \overrightarrow{\boldsymbol{n}}}_{\text {Barotropic force }}-c(t) \underbrace{\int_{z}^{\eta} \frac{\rho-\rho_{0}}{\rho_{0}} d z}_{\text {Baroclinic force }} \overrightarrow{\boldsymbol{n}} \\
& -\underbrace{\underbrace{p_{\text {atm }}}_{\rho_{0}} \overrightarrow{\boldsymbol{n}}}_{\text {Atm pressure }}+\underbrace{\Phi \overrightarrow{\boldsymbol{n}}}_{\text {Gravitational potential }}+\underbrace{c(t) \overrightarrow{\boldsymbol{\tau}}}_{\text {Surface and bottom stress }}) d S .
\end{aligned}
$$

$V$ is an orientable control volume fixed relative to the reference frame origin; $A$ is its surface and $\vec{n}$ is its outwards normal vector. $S S_{T}$ and $S S_{S}$ are the source and sink terms of their respective properties. They take into account the sensible and latent heat as well as solar radiation with light penetration in the temperature equation. $p_{\text {atm }}$ is the atmospheric pressure, $\Phi$ is the gravitational potential which is the sum of the Earth gravitational potential with the astronomical tide potential. $g$ is the vertical component of the gravitational pull near the Earth's surface, where it is considered constant. $\vec{\tau}$ represents the wind and bottom stresses which are calculated proportionally to the square of the relative velocity between interfaces. $\frac{\partial}{\partial t}$ is the explicit time derivative, $z$ is the vertical coordinate and $\vec{\nabla}$ is the gradient operator. $c(t)$ is a ramp coefficient function, devised to slowly activate the baroclinic force and the surface stress during the spin-up period, defined by $\frac{t}{T_{c}}$ if $t<T_{c}$, otherwise it is equal to one. The ramping period $T_{C}$ is set to six inertial periods (rotation period of the Earth). $\overrightarrow{v_{T} \nabla} \equiv\left(v_{H} \frac{\partial}{\partial x}, v_{H} \frac{\partial}{\partial y}, v_{V} \frac{\partial}{\partial z}\right)$ is a vector combination of the turbulent viscosity vector $\overrightarrow{v_{T}}=\left(v_{H}, v_{H}, v_{V}\right)$ with the gradient operator. Analogous vector combinations are made with the temperature and salinity turbulent diffusion vectors, respectively $\overrightarrow{K_{T}}$ and $\overrightarrow{K_{S}}$. Turbulent diffusion is determined separately between its horizontal component and vertical component, often being used as constant turbulent diffusions along the horizontal for regional ocean applications, whereas a higher order turbulent closure model is usually chosen to determine the vertical turbulent diffusions. The equations for the vertical turbulent kinetic energy and the eddy dissipation rate due to viscosity (Burchard, 2002) are solved using the GOTM (General Ocean Turbulence Model) solver (Ruiz-Villarreal et al., 2005), embedded in the MOHID code, from which the model parameterized according to Canuto et al. (2001) is chosen.

The MOHID model uses a finite volume approach to discretize the equations in a curvilinear structured grid. In this approach, the discrete form of the governing equations is applied macroscopically to a cell control volume. This makes the actual way of solving the equations independent of cell geometry and allows the use of a generic vertical coordinate (Martins et al., 2001; Martins et al., 1998). The equations are discretized horizontally on an Arakawa-C staggered grid (Arakawa, 1966). All types of vertical coordinates have a wetting/drying cell scheme. The model solves a semi-implicit ADI (Alternating Direction Implicit) algorithm to compute the sea level evolution with two time levels per iteration, following the method proposed by Leendertse (1967). The two components of the horizontal velocity are globally centred in time, $\mathrm{t}+\mathrm{dt} / 2$, leading to a second order time accuracy (Martins et al., 1998, 2001). Advection and diffusion of tracer properties such as temperature and salinity are computed explicitly in the horizontal and implicitly in the vertical. A conservative scheme is used for the advectiondiffusion of all properties, consisting in a weighted average between first-order and third-order upwind with TVD (Total Variation Diminishing) flux limiters for advection, whereas central differences are used for diffusion. For the baroclinic 
force, the MOHID model uses a z-level approach for any type of vertical coordinate. This methodology integrates the horizontal density gradient always in the Cartesian space. The bottom stress is calculated semi-implicitly for numerical stability reasons.

\subsection{Model setup}

The online one-way nested modelling system consists of two model configurations. First, a 2-D barotropic model with $0.06^{\circ}$ of resolution forced only with the FES2004 (Finite Element Solution) tidal atlas (Lyard et al., 2006; Lefèvre et al., 2002), using a Blumberg and Kantha (1985) radiation scheme and covering the geographic area $33.5^{\circ} \mathrm{N}-$ $45.9^{\circ} \mathrm{N}$ and $13.5^{\circ} \mathrm{W}-4.2^{\circ} \mathrm{W}$. Second, the 2-D (two dimensional) model becomes the online external reference tidal solution to the West Iberia 3-D (three dimensional) baroclinic model with the same horizontal resolution, covering the region $34.4^{\circ} \mathrm{N}-45.0^{\circ} \mathrm{N}$ and $12.6^{\circ} \mathrm{W}-5.5^{\circ} \mathrm{W}$ (Fig. 1) and with 50 vertical layers, where the bottom 43 are in Cartesian coordinates and the top $10 \mathrm{~m}$ are 7 sigma coordinate layers. The Cartesian coordinate is not limited like a sigma coordinate over variable topography and steep slopes. Indeed, sigma coordinate is known to induce spurious up-sloping velocities due to the pressure gradient term (Beckmann and Haidvogel, 1993). Therefore, the Cartesian coordinate is a practical choice in a domain characterized by an abyssal plain, a continental shelf, a very steep shelf slope and large canyons. On the other hand, coastal upwelling and freshwater buoyant plumes coming from river discharges are two regional features that yield complex stratification patterns near the surface and, thus, require a good vertical resolution. The sigma coordinate has the advantage of being a topographicallyfollowing coordinate and, thus, provides the same vertical relative resolution near the surface, either in areas with $10 \mathrm{~m}$ depth or less than $1 \mathrm{~m}$.

The bathymetric baseline data for both 2-D and 3-D models is the SRTM 30" database. The 3-D model is also forced with a full offline baroclinic solution, the Mercator-Océan Psy2V3 (Psy 2 stands for the Greek letter followed by an integer which codenames a specific region of the NorthAtlantic, whereas V3 stands for version 3 of the system) hindcast and forecast for Western Iberia (Cailleau et al., 2010; Drillet, 2005) until December 2010 and the MercatorOcéan Psy2V4 (the upgraded version of the same region) from January 2011 onwards, with a coarser horizontal resolution than the MOHID model domain $\left(1 / 12^{\circ}\right)$ and with the same vertical Cartesian coordinate discretization (to reduce interpolation errors). The absence of tide in the Mercator solution is handled by linearly superimposing the 2-D model tidal reference solution to the Mercator reference solution according to the methodology described by Leitão et al. (2005). Specifically, it consists of performing a mathematical sum at open boundaries of the reference solutions for the level and for the velocities linearly interpolated every time step of the

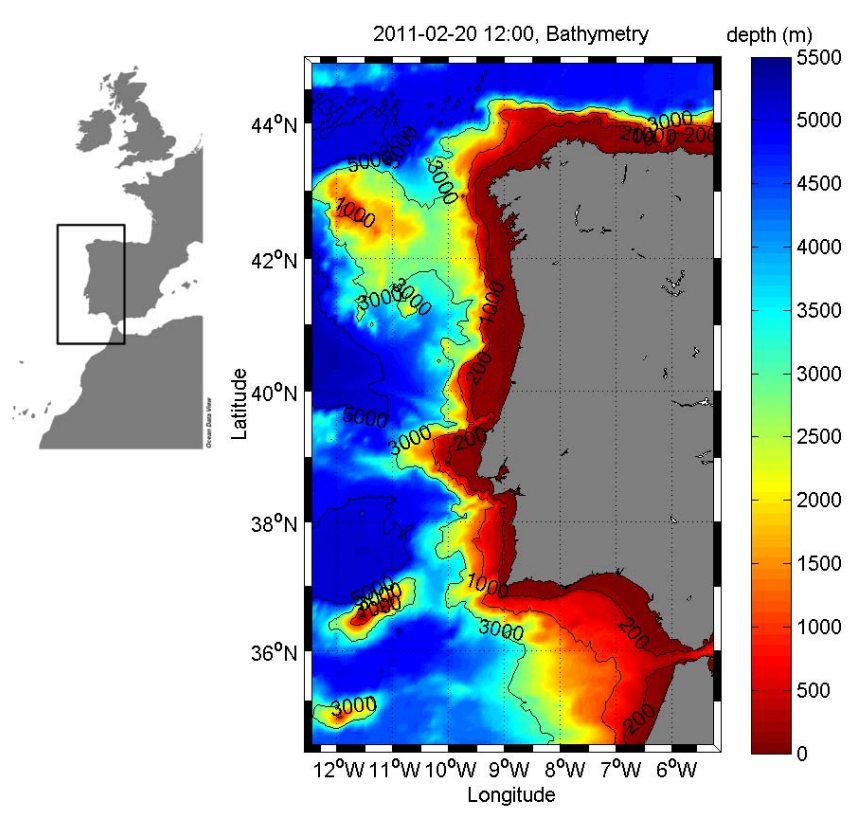

Fig. 1. West Iberia baroclinic model bathymetry bounded by $5.5^{\circ}-$ $12.6^{\circ} \mathrm{W}$ and $34.4^{\circ}-45.0^{\circ} \mathrm{N}$, and with a $0.06^{\circ}$ spatial resolution. Baseline data from SRTM 30".

model. The composite tidal reference solution is then applied with a Flather (1976) radiation scheme to the 3-D model. The 3-D model is then submitted to a FRS (Flow Relaxation Scheme) to the Mercator solution for $u, v, S$ and $T$, following the methodology described in Martinsen and Engedahl, 1987.

A ten-cell width frame at the border is setup where an exponentially decreasing relaxation time scale is applied, ranging from $3 \times 10^{4} \mathrm{~s}$ inside the domain to $10^{8} \mathrm{~s}$ close to the open boundary. The flow relaxation scheme adds small corrections to the model results by diminishing deviations from the reference solution (in occurrence, the reference is the Mercator-Océan baroclinic solution composed linearly with the FES2004 tide solution). In particular, this should allow for eddies coming from outside the domain to spread inside the nested domain. However, eddies generated inside the domain that are absent from the reference solution are not suited to be transported outside of the domain, and instead are dissipated by the kinetic energy dissipation rate. Discrepancies between the reference solution and the model solution near the open boundary are expected as both models were setup with different surface forcing and contain different physical processes (tide is absent in the Mercator-Océan solution). In practice, model results residing inside the ten-cell width frame should be considered as part of the open-boundary system.

Initialization of the 3-D fields of temperature and salinity are made by a direct interpolation of the MercatorOcéan fields for $T$ and $S$. A bilinear interpolation in the horizontal and linear interpolation in the vertical and in time 
are assumed. For the extrapolation procedure, the nearestneighbour approach was used. Both models have 50 identical layers. Additionally, a null velocity field and sea level field with null gradient are assumed. For the spin-up procedure, a methodology based on a ramped increase in forcing (baroclinic force, wind stress) was implemented (Leitão et al., 2005).

Furthermore, the system is one-way coupled offline with the atmospheric forecast model MM5 (Mesoscale Meteorological Model 5) running at IST (Sousa, 2002; http://meteo. ist.utl.pt) for the West Iberian coast, providing forecast of 10 $\mathrm{m}$ height wind speed, air temperature, mean sea level pressure, surface humidity, cloud cover, downward long wave radiation and solar radiation with a spatial resolution of $9 \mathrm{~km}$ and with hourly frequency. The atmospheric model is forced with the forecasts provided by the GFS (Global Forecast System). The surface heat flux is parameterized using bulk quantities of both the atmosphere and water. The net shortwave and the downward longwave radiation terms are provided directly by the atmospheric model, while the upward longwave radiation and the turbulent fluxes are calculated by the hydrodynamic model using its own SST (sea surface temperature) and the relevant atmospheric parameters. Changes in water volume due to evaporation and precipitation are ignored. River runoff is a very important feature, particularly in the study of surface coastal circulation where buoyant freshwater plumes pay an important contribution. At this point, it is absent in the regional model, but will be added soon in the next version to come. A biharmonic filter (Delhez and Deleersnijder, 2007) replaces horizontal turbulent viscosity in the model configuration.

\subsection{MOHID-PCOMS operational system}

Since its first introduction as a pre-operational model (Riflet et al., 2008), the West Iberian coast model has evolved and is now running daily in full operational mode with a 3-day forecast and keeps a best-guess result historical timeline. This operational system, consisting of the numerical model setup described above, along with Visual Basic and MATLAB scripts and an OPeNDAP/THREDDS (Open-source Project for a Network Data Access Protocol/Thematic Realtime Environmental Distributed Data Services) server running in a hybrid Windows/Linux operating system network environment, is called MOHID-PCOMS. Best-guess results are disseminated to the internet, where data is made freely available at http://opendap.mohid.com:8080/thredds/catalog.html in the scope of EASYCO European project (COllaborative European Atlantic water quality forecasting SYstem). The new MOHID-PCOMS operational system is built such that it can easily be replicated to other domains with different regional scales. Currently, a number of local models are coupled to the MOHID-PCOMS in offline mode, with a similar methodogy used as for the MOHID-PCOMS. They also provide 3-day forecast with historical best-guess hindcast. The results of the these models at the local scale have a potential of utility for civil institutions and the general public, but also are of interest to the scientific community, in particular regarding coupled physical-biogeochemical research. Both their domains and their utility will be addressed ahead.

\section{The results: a brief description of model behaviour}

Two examples of the forecast have been selected to demonstrate the operation of the MOHID-PCOMS regional forecasting system, which adds the tide when compared to the Mercator-Océan solution. These examples correspond to winter and summer seasons when circulation features and temperature patterns are different from each other. Accurate river discharges are soon to come and should also improve the surface and subsurface results over the continental shelf when compared with the Mercator-Océan solution.

\subsection{Forecast for winter season}

Sea surface temperature and salinity fields predicted by the model for the winter conditions are presented in Fig. 2 and Fig. 3. Horizontal distribution of the temperature is typical for the winter period, with a range between $11-18^{\circ} \mathrm{C}$ and a strong north to south gradient, with warmer waters observed in the southern area. Colder water near-shore is particularly visible along the SW (south-west) coast, denoting the existence of a winter episode of wind induced upwelling front. Winter upwelling events are unusual in the area since northerly winds prevail mostly during summer, which is when the Azores anti-cyclone centre (a prominent process that influences the wind patterns over Iberia and the whole European Atlantic arc) moves northward; however, they do happen and there are some studies addressing them (Varela et al., 2010). Likewise, salinity also shows a marked north to south gradient, with higher salinity values associated with warmer water masses present in the south of the domain.

There is a great deal of variability in the domain with meandering water masses of different temperature and salinity and some clear eddy formations and jet currents parallel to the coast. The surface current field for the modelled domain is shown in Fig. 4. During the forecasting interval, the regional circulation is characterized by intense formation and deformation of eddies. This process is evident in the chain of eddies that occur along the domain. Cyclonic and anticyclonic eddies are typical elements of the regional circulation, with diameters around 100 to $200 \mathrm{~km}$ and covering a significant part of the southern part of the domain. These eddy formations, usually associated with the wind regime, are not stable formations and decompose or undergo some modifications in time. There is a clear southward coastal jet that can be explained by the north wind circulation observed in this period (not show here). Also, the cold waters observed in the 

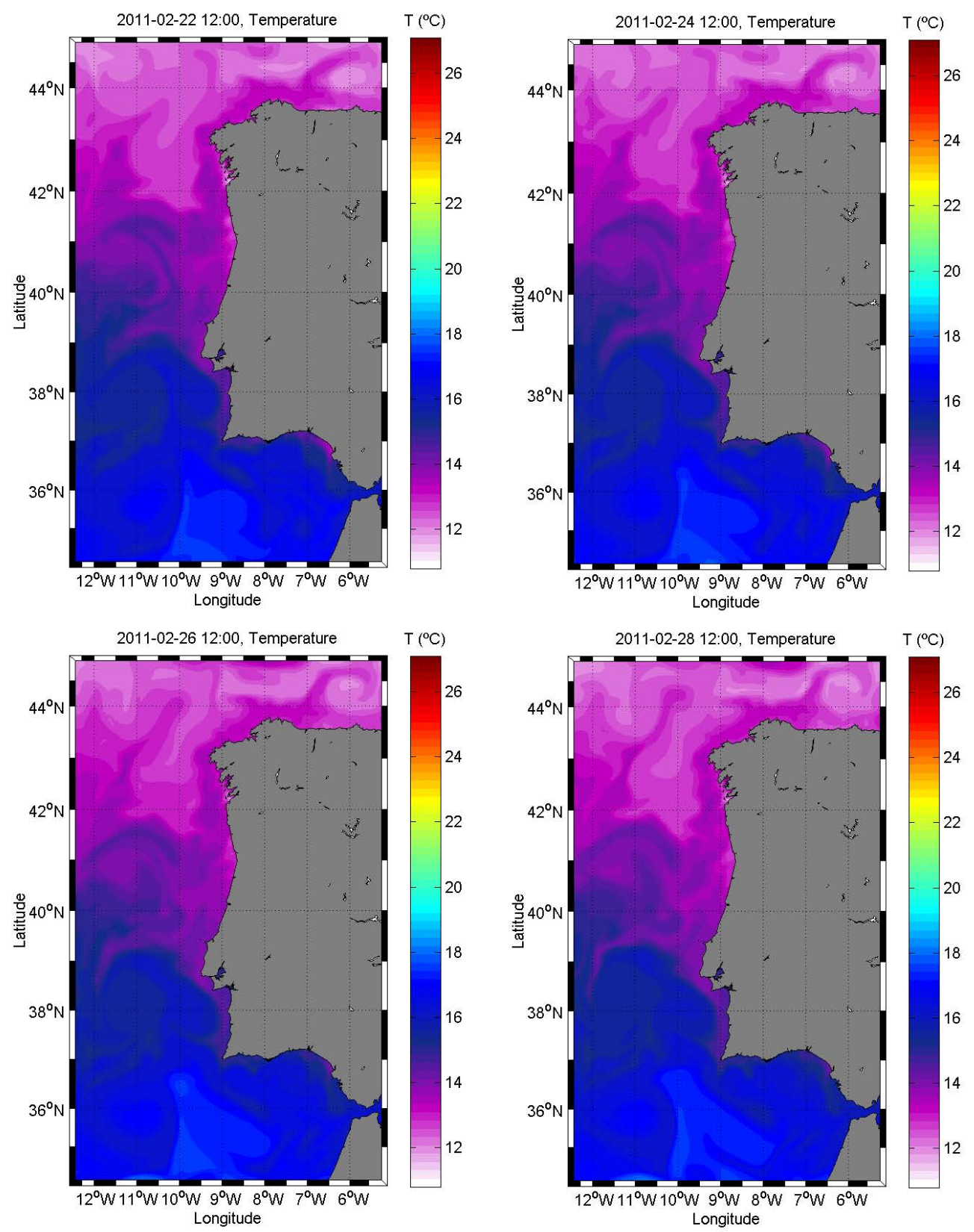

Fig. 2. Snapshots of sea surface temperature predicted by the model from 22 to 28 February 2011.

temperature results for the same location denote the presence of an upwelling episode.

\subsection{Forecast for summer season}

The second example of forecast concerns the summer period between 4 and 10 July 2011. Model predictions for the horizontal distribution temperature and salinity are shown in Fig. 5 and Fig. 6, respectively. The surface waters gradually warm up until the end of spring, but the southward temperature gradient is still evident. By the beginning of July, temperatures throughout the domain are between 17 and $23^{\circ} \mathrm{C}$, with the exception of the coastal area in Cape Finisterre where upwelled waters are around $13{ }^{\circ} \mathrm{C}$, and in the south of the domain where lenses of warm water reaches values between 24 to $27^{\circ} \mathrm{C}$. Throughout summer the surface temperatures keep this range of variation in the domain. Salinity follows the same general pattern as in the winter forecast, with higher values observed in the south of the domain.

Upwelling is a typical feature along the coast of Portugal, and the model results show that the model is able to reproduce this oceanographic process. The intensification of the upwelling front along the coast is clearly seen in Fig. 5, and 

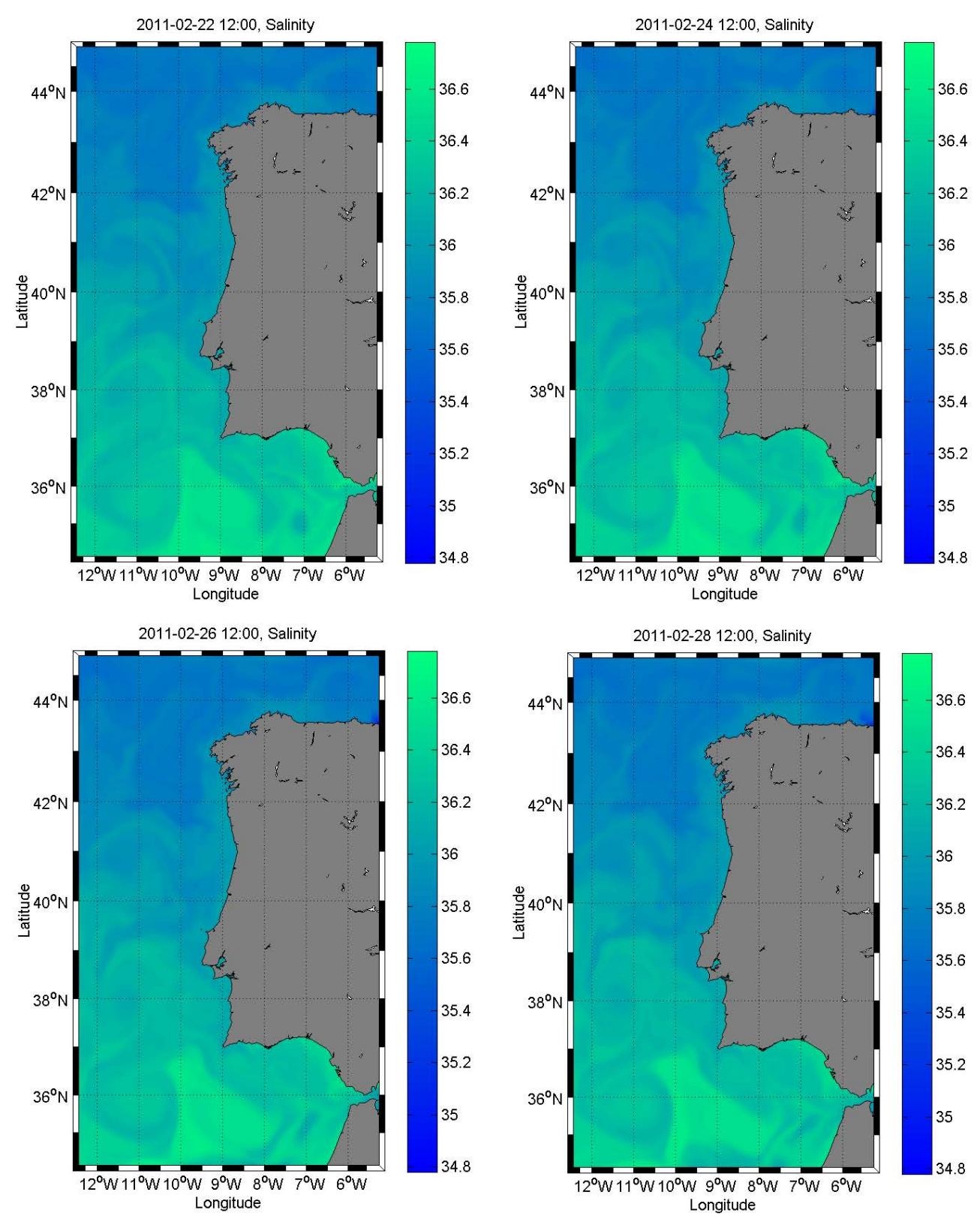

Fig. 3. Snapshots of sea surface salinity predicted by the model from 22 to 28 February 2011.

by the 10th of July it is well depicted in the south-western tip of Portugal around the St. Vicente cape.

The surface velocity pattern for the analysed summer period is shown in Fig. 7. It is interesting to note that the regional circulation pattern is different from the winter circulation. The general structure of the regional circulation during this period is characterized by a lower number of eddies with reduced radius, as expected during summer warming of the upper layer. Nevertheless, a southward coastal current is also observed as a result of the upwelling regime observed in this time period, with higher velocity values particularly noticed on the NW (north-west) coast.

\section{Discussion}

\subsection{Model validation}

Model validation is usually implemented through comparing model results with observations from remote sensors and insitu platforms and instruments. However, as frequently reported in similar studies (e.g. Siddorn et al., 2007; Oddo and Guarnieri, 2011), there is a continuing challenge with attempting validation exercises because availability of adequate in-situ data is usually poor, and when it exists it is often hard to access in a reasonable timeframe. In this study 

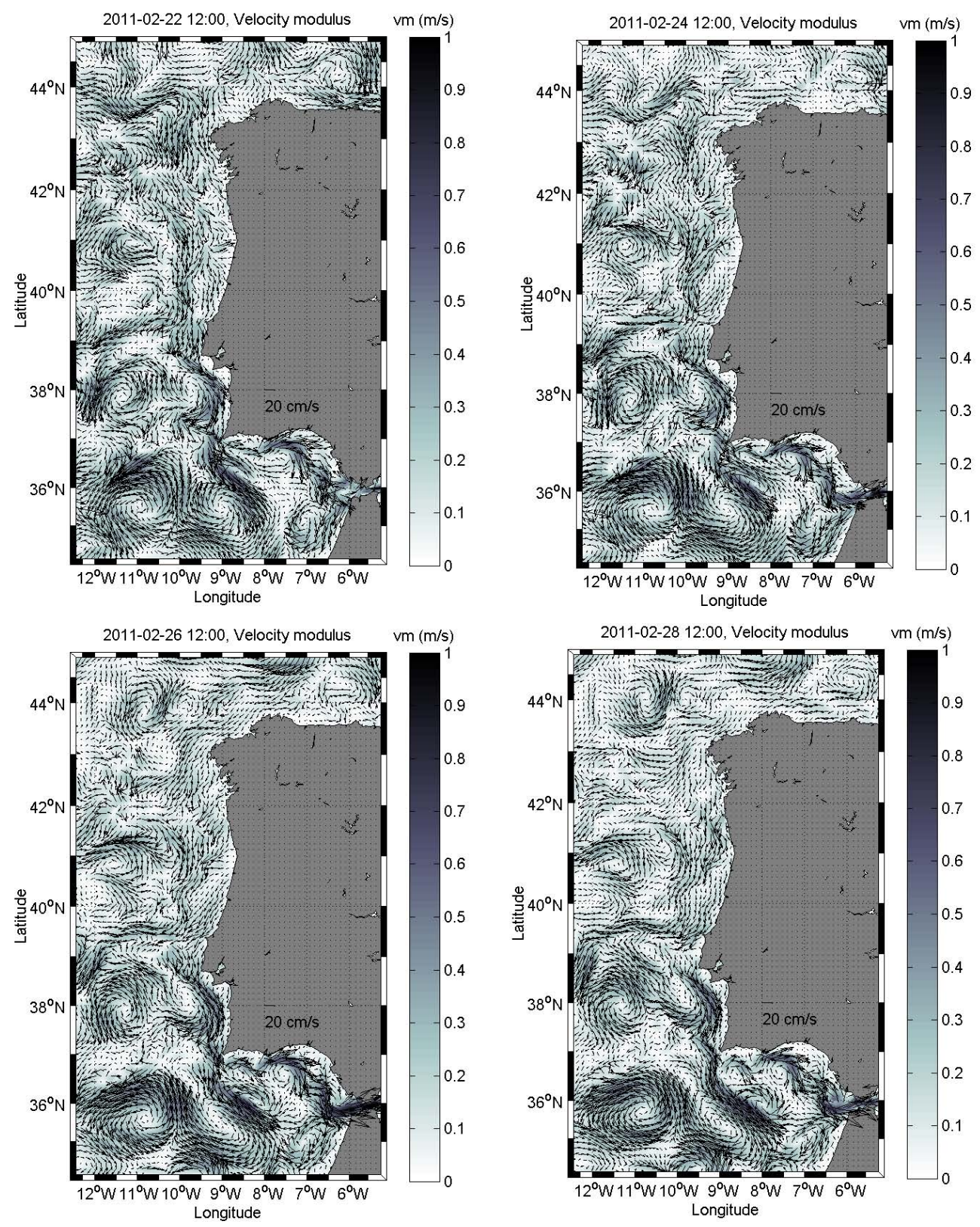

Fig. 4. Snapshots of sea surface current field predicted by the model from 22 to 28 February 2011.

quantitative validation of the best-guess simulated 2-D surface fields as well as selected best-guess vertical temperature and salinity profiles are carried out using regular satellite remote sensing measurements and deep profiling floats (see Korotaev et al., 2011).

Efforts are made to validate the physical properties of the model by comparing simulated SST with remote sensing data on a systematic basis. For the SST data, merged infrared and microwave sensor products were used because they provide information in regions with frequent cloud cover. The products came from the Mediterranean Sea Ultra High Resolution Sea Surface Temperature Analysis
(MyOcean catalogue product ID: SST-MED-SST-L4-NRTOBSERVATIONS-010-004-a).

In this analysis the root mean square error (RMSE) and the bias are estimated to assess model performance and predictive skill, producing daily statistics and a weekly summary report. The calibration process is done in a 2-step approach: (1) the area-averaged (i.e. the entire modelled domain) and daily/monthly averages are compared, and simple statistics, such as the regression equation parameters and RMSE, are calculated; (2) the spatial variability is included by re-gridding model predictions into the satellite data grid, and statistics are calculated for every grid node for 

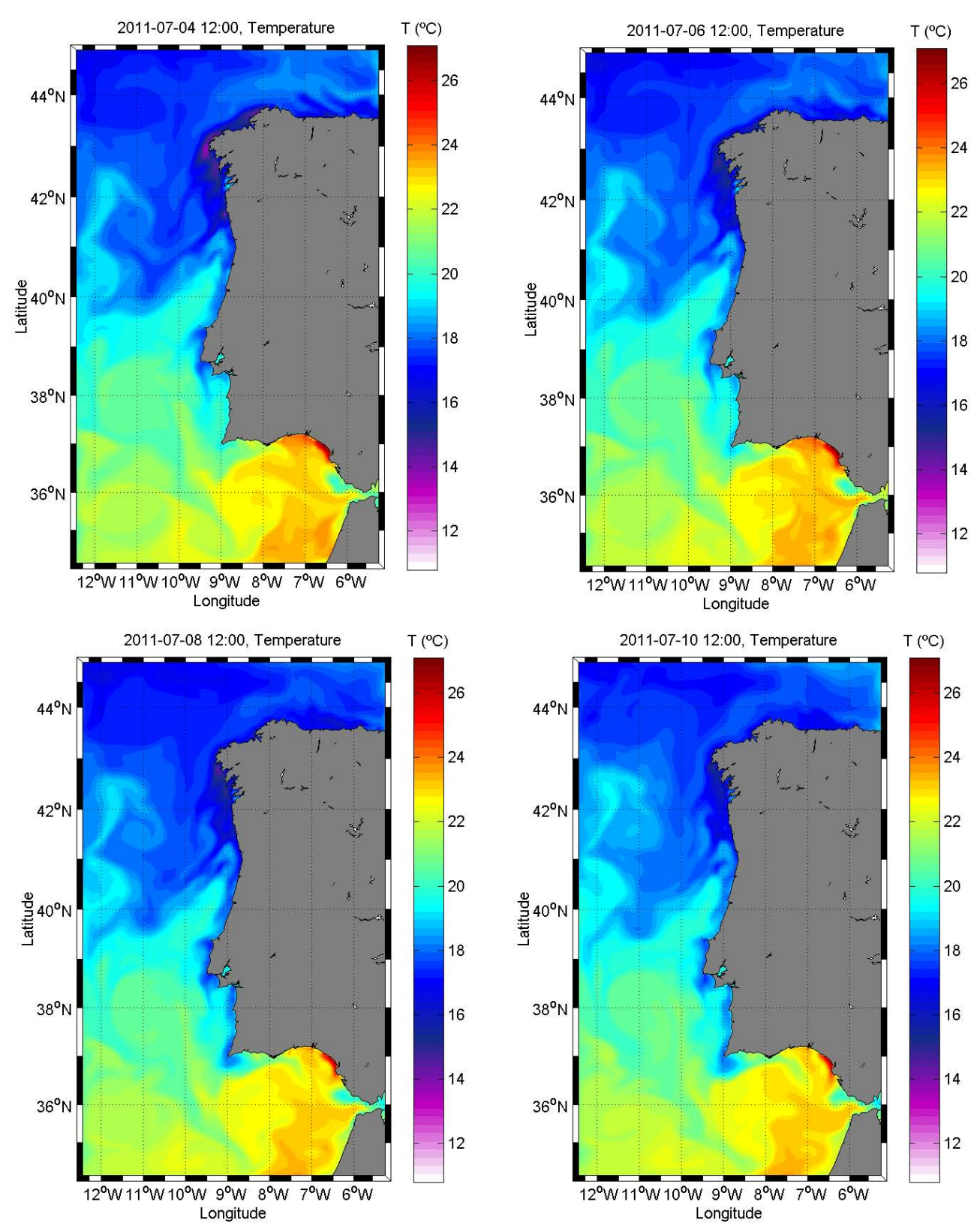

Fig. 5. Snapshots of sea surface temperature predicted by the model from 4 to 10 July 2011.

monthly averaged data. However, some considerations must be taken into account when comparing model results with remote-sensing imagery. The skin temperature is regarded as the temperature of the model that should be compared with remote-sensing SST imagery but is not a direct output of the model. On the other hand, the bulk temperature, which is the average temperature of the layers, is a direct output of the model. The bulk temperature should be post-processed to generate a skin temperature. Currently, only bulk temperature of the surface layer is compared with remote-sensing SST imagery and skin temperature is not computed, i.e. sur- face layer bulk temperature is a proxy for skin temperature.

Likewise, comparisons between model results of temperature and salinity depth profiles and Argo floats from IFREMER are performed on a regular basis. Argo data for temperature and salinity is freely available in real time by FTP (file transfer protocol) downloading (ftp://ftp.ifremer. fr/ifremer/argo/geo/). A preliminary validation and control quality check is performed on the data before the validation process. This control excludes temperature and salinity values higher than pre-defined values that correspond to a range known for the study area. Model output is interpolated in 

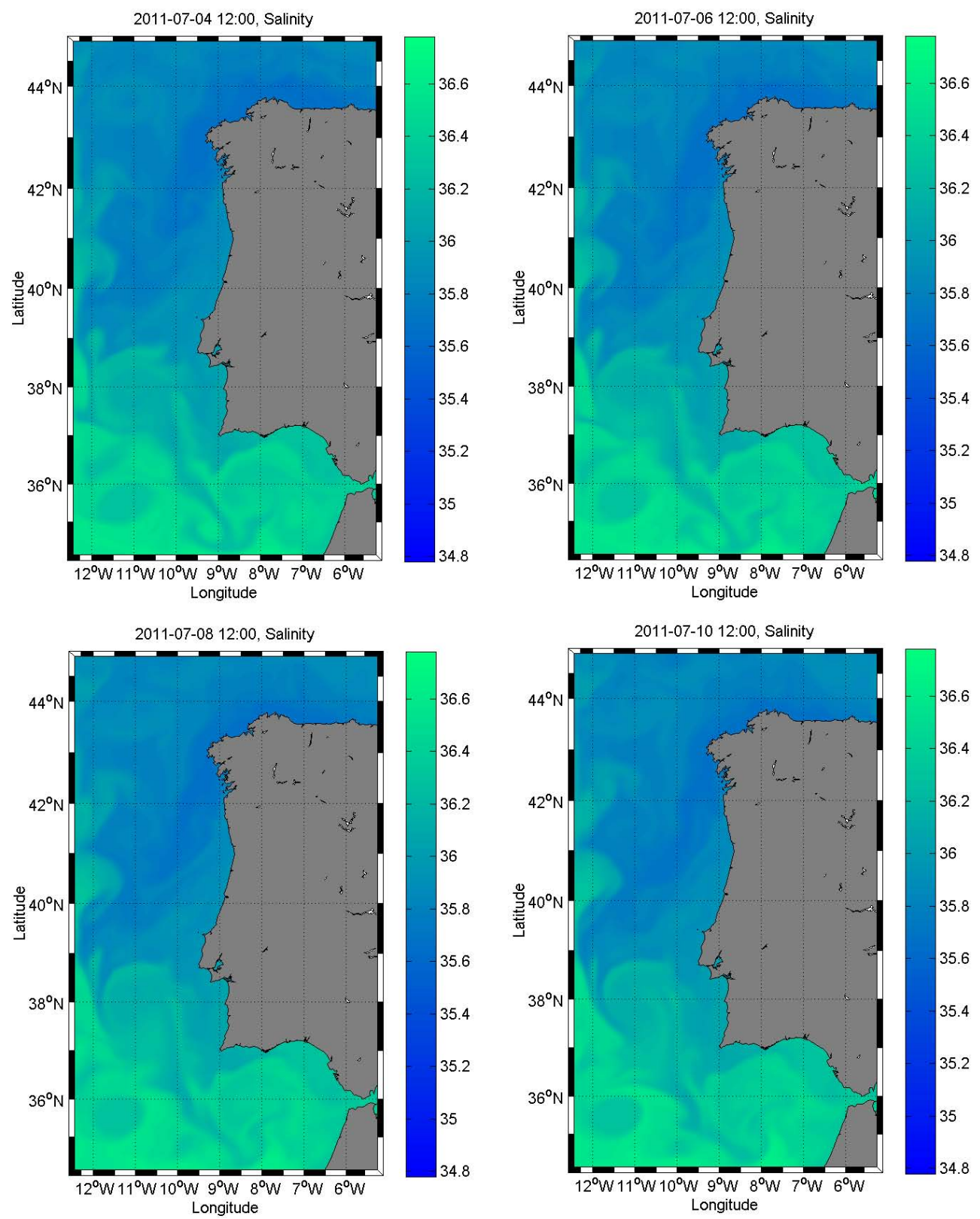

Fig. 6. Snapshots of sea surface salinity predicted by the model from 4 to 10 July 2011.

time and space (linear interpolation) for the position of the buoy (for all vertical levels), and statistical analyses are performed (bias, RMSE, $r$, etc.) for both profiles. This procedure is performed for temperature and salinity separately. A $T-S$ diagram (Temperature-Salinity) is constructed with the Argo data and another with the model data, and both are compared visually. Some examples of validation of forecasted SST are shown in Fig. 8 and Fig. 9 for the days 25 February and 7 July, respectively, which are considered in the next subsection analysing forecast results. The figures show that simulated and observed surface temperature fields are in a good agreement to each other. Both the simulated and measured
SST patterns for 25 February equally reflect the main features of the temperature field, namely the north to south gradient of temperature characterized by higher temperature in the south and decreasing northward. Also, both model results and data show lower temperature values along the southern and south-western coasts of Portugal. Validation results show that the model simulates adequately the thermodynamics of the top sea layer.

Likewise, the simulated and measured SST for the summer conditions show considerable agreement with a common tendency of surface warming towards the south. A fairly common seasonal phenomenon is also depicted in both surface 

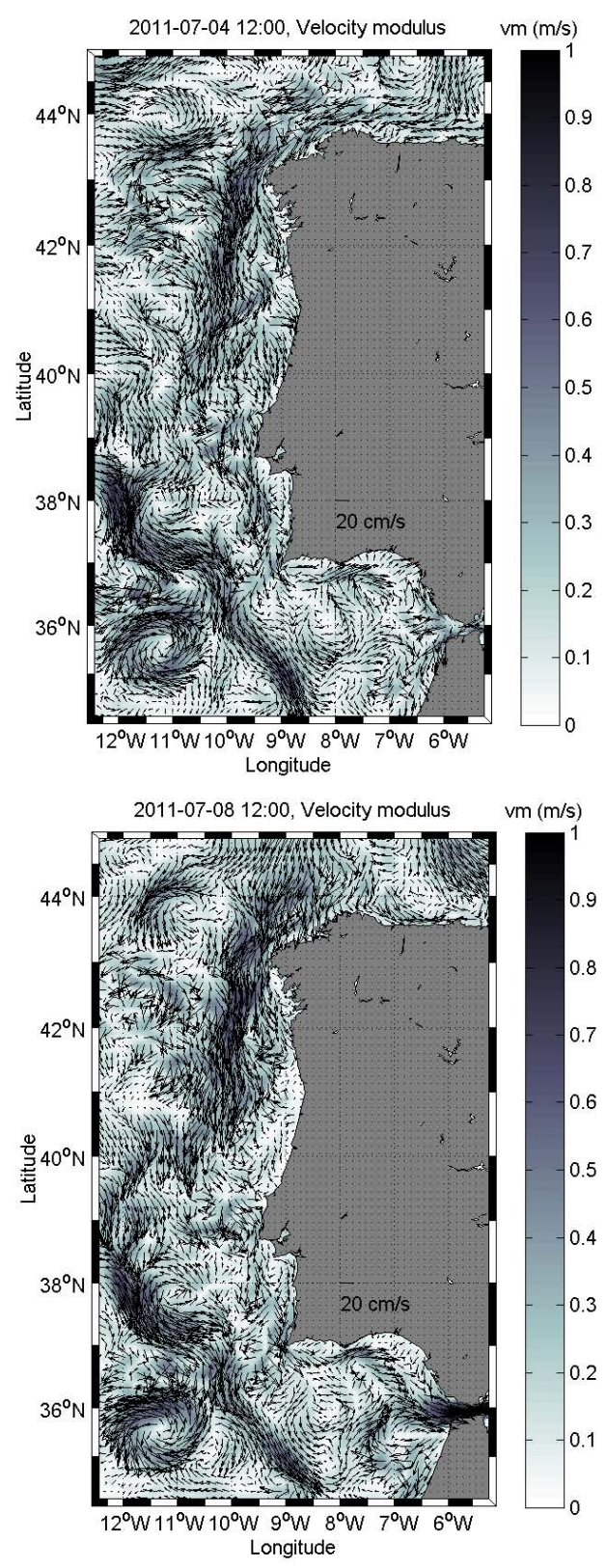
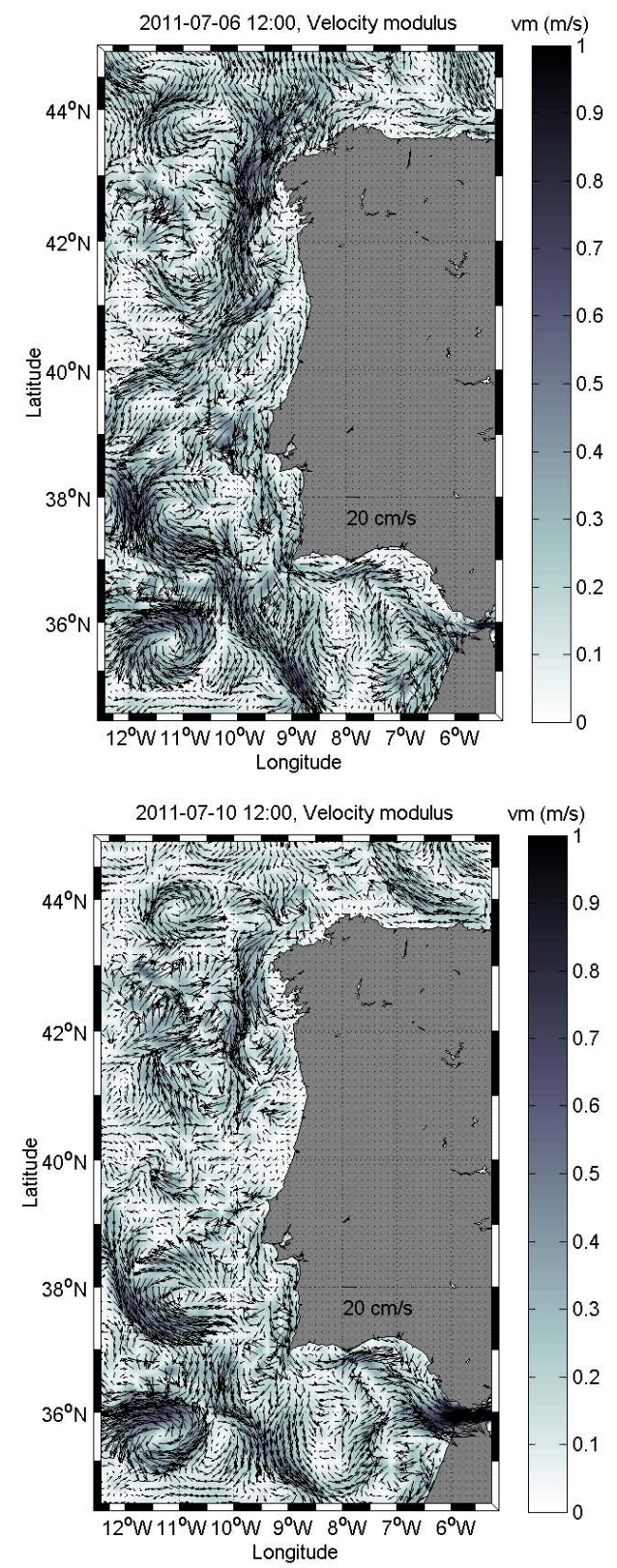

Fig. 7. Snapshots of sea surface current field predicted by the model from 4 to 10 July 2011.

fields, namely the cold water mass along the west coast as a result of wind-induced upwelling.

Statistics were calculated by averaging over the entire modelled domain. The mean difference in the two winter maps (Fig. 8) is equal to $-0.008{ }^{\circ} \mathrm{C}$, with RMSE equal to $0.467{ }^{\circ} \mathrm{C}$ and the correlation coefficient 0.961 . The difference between measured and simulated SST in most parts of the area is in the range of $\pm 1.5^{\circ} \mathrm{C}$, with more significant differences occurring in the vicinity of frontal zones, as would be expected due to miss-location of the front in the two fields. In comparison, the corresponding mean difference in the two summer maps (Fig. 9) is equal to $0.22^{\circ} \mathrm{C}$, with a RMSE of $0.726^{\circ} \mathrm{C}$ and a correlation coefficient of 0.941 . In this case the difference between measured and simulated SST in most parts of the area is in the range of $\pm 2{ }^{\circ} \mathrm{C}$.

Temperature and salinity profiles are also compared with data from Argo profiling floats (Fig. 10 and Fig. 11). In addition to visual comparison, a simple statistical analysis is provided. The comparison shows a good fit between model results and data. The simulated salinity profiles differ more significantly from measurements than the temperature profiles do, but still do not exceed 0.3 ppt. The correlation coefficients of simulated and observed temperature and salinity profiles are high for both summer and winter conditions. 


\section{MOHID SST vs Satellite SST 2011-02-25}
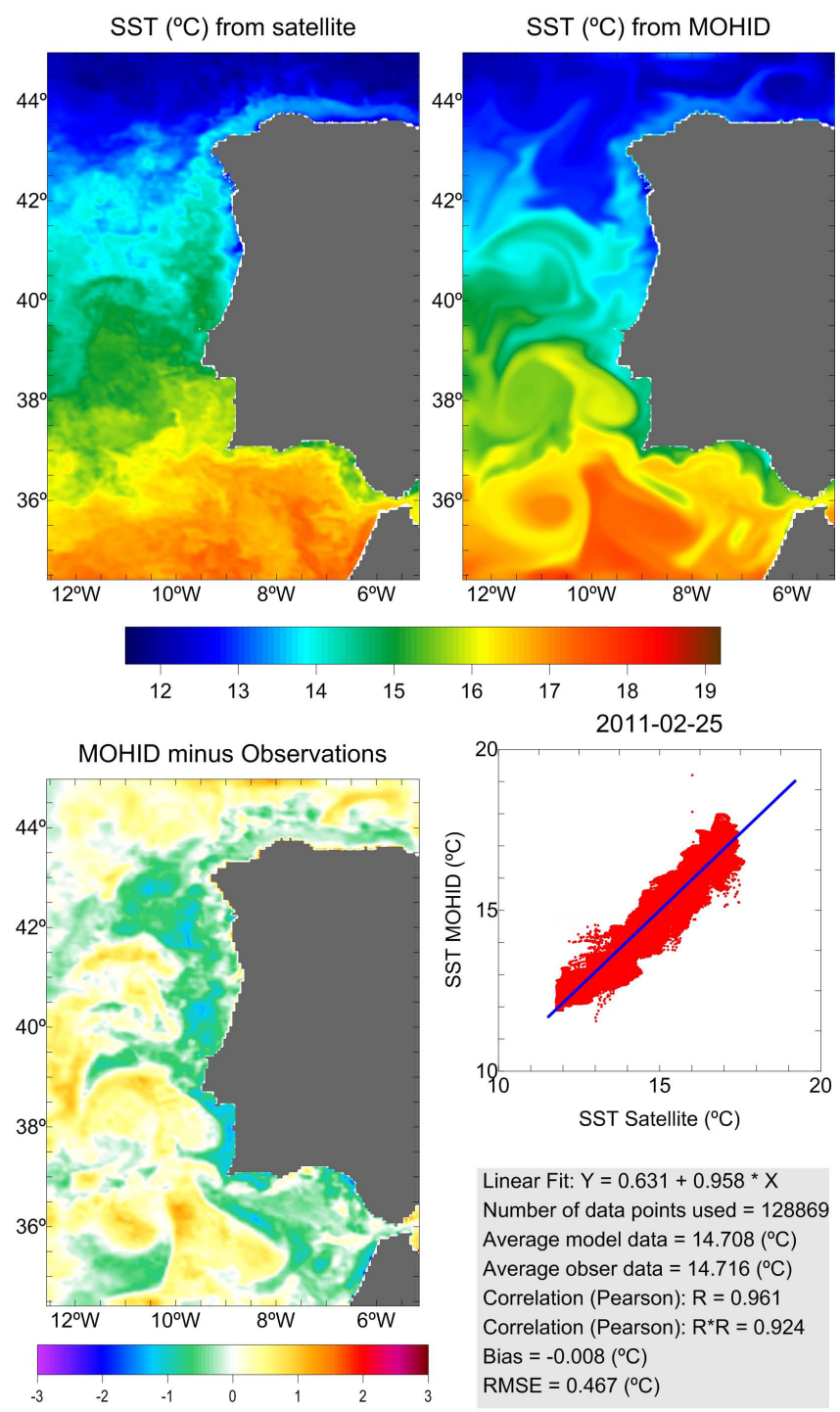

Linear Fit: $Y=0.631+0.958 * X$ Number of data points used $=128869$ Average model data $=14.708\left({ }^{\circ} \mathrm{C}\right)$ Average obser data $=14.716\left({ }^{\circ} \mathrm{C}\right)$ Correlation (Pearson): $\mathrm{R}=0.961$ Correlation (Pearson): $R^{\star} R=0.924$ Bias $=-0.008\left({ }^{\circ} \mathrm{C}\right)$ RMSE $=0.467\left({ }^{\circ} \mathrm{C}\right)$

Fig. 8. Sea surface temperature (SST) maps on 25 February 2011 retrieved from remote sensing data (upper left panel), simulated by the model (upper right panel), and their difference (lower pannel). Linear fit between model and data, and results from basic statistical analysis are also shown.

The comparisons show good qualitative and quantitative agreement between the forecasted and observed temperature fields. In most cases the difference does not exceed $1.5^{\circ} \mathrm{C}$, but sometimes there are some marked differences in nearshore areas where the spatial resolution of the model imposes some limitations. This is an expected outcome since offshore regions often validate better than near-shore ones (Holt and James, 1999).

Differences of up to $0.5^{\circ} \mathrm{C}$ are expected between different satellite sensors and between satellite and in-situ measure-
MOHID SST vs Satellite SST 2011-07-07
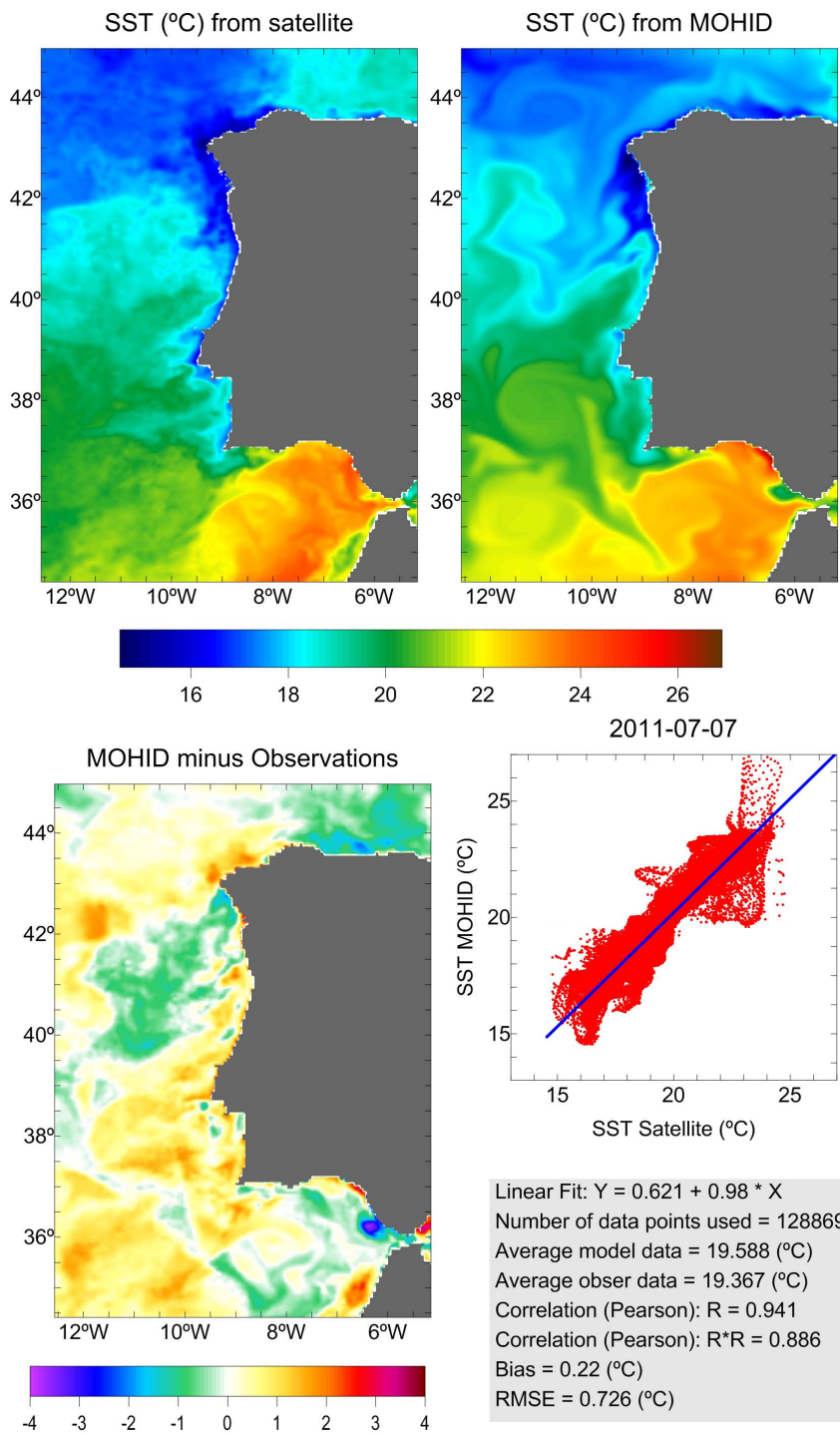

Linear Fit: $Y=0.621+0.98 * X$ Number of data points used $=128869$ Average model data $=19.588\left({ }^{\circ} \mathrm{C}\right)$ Average obser data $=19.367\left({ }^{\circ} \mathrm{C}\right)$ Correlation (Pearson): $\mathrm{R}=0.941$ Correlation (Pearson): $R^{*} R=0.886$ Bias $=0.22\left({ }^{\circ} \mathrm{C}\right)$ RMSE $=0.726\left({ }^{\circ} \mathrm{C}\right)$

Fig. 9. Sea surface temperature (SST) maps on 7 July 2011 retrieved from remote sensing data (upper left panel), simulated by the model (upper right panel), and their difference (lower pannel). Linear fit between model and data, and results from basic statistical analysis are also shown.

ments. These differences can be attributed to surface winds, diurnal warming, satellite manoeuvres and algorithm selection. The mixed layer is a surface layer that is present in the ocean and in lakes and that is well mixed, i.e. that has homogeneous temperature. The mixed layer undergoes seasonal variations, and the processes involved in its generation are predominantly wind and waves. During summer months there usually is a thinner mixed layer as compared to winter months when storm conditions occur more often. Thus, during summer when the mixed layer is thinner, the model vertical resolution required to accurately reproduce it is higher 


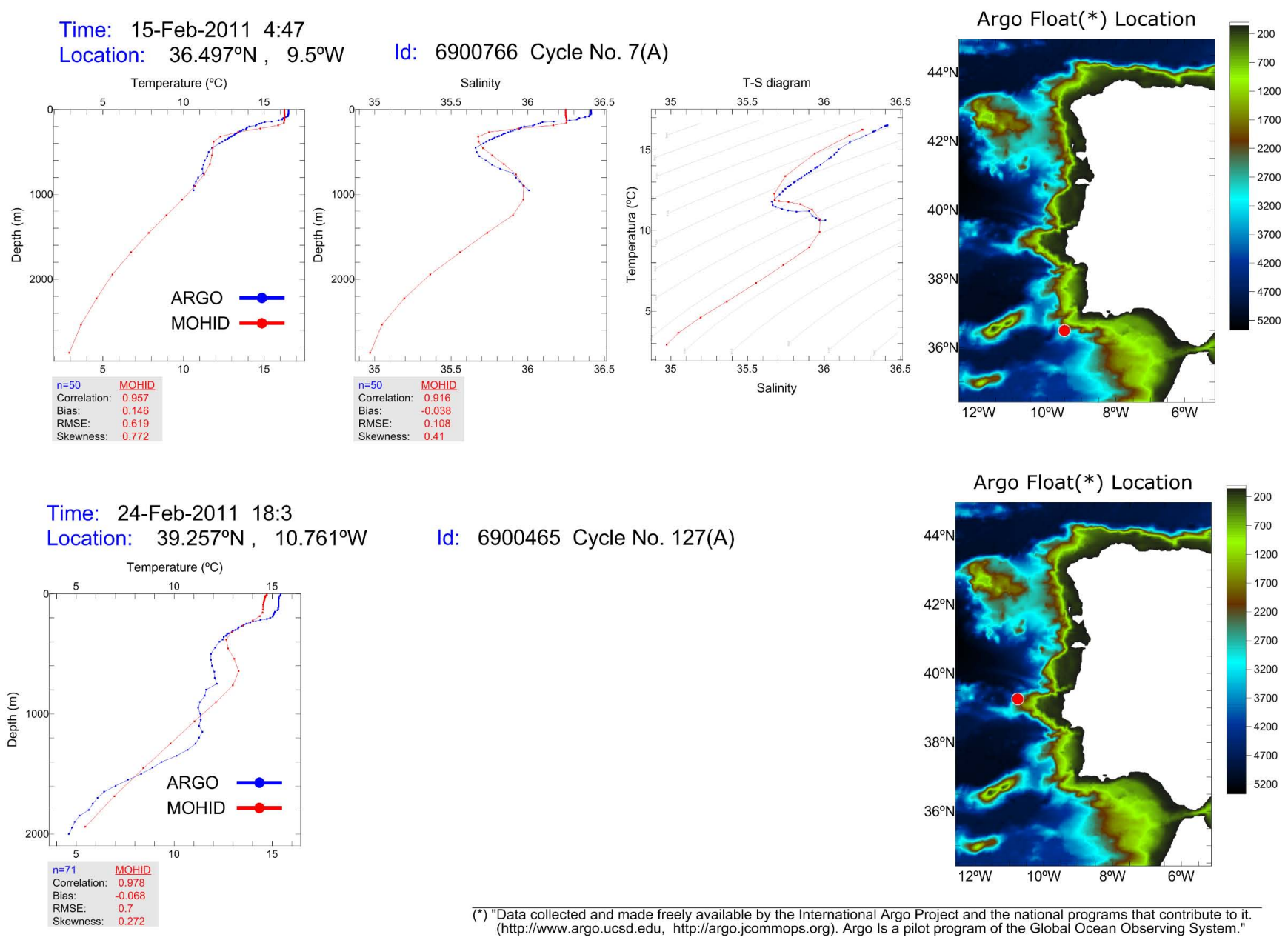

Fig. 10. Simulated temperature and salinity profiles for February 2011 compared with Argo data. The locations of the buoy are represented in the maps by a red circle. Statistical results are also present for each parameter.

than during winter. So, it is argued that a higher error is yielded in the model during summer when modelling the mixed layer at the surface. Therefore, a higher difference is expectable during summer between the model top layer bulk temperature and the satellite SST. This difference between seasons is seen in the results.

Based on the presented results, the predicted sea surface temperature (Fig. 8 and Fig. 9) compares well with measurements, underlining the capacity of the hydrodynamic model and the adequateness of the high resolution surface forcing and good lateral boundary conditions. An exhaustive validation of SST is now underway and will allow a detailed assessment of model performance.

Validation using Argo profiling floats (Fig. 10 and Fig. 11) suggests that the model reproduces reasonably well features such as upper layer thermodynamics, vertical stratification of thermohaline fields and the permanent pycnocline. However, a conclusive result on the skill of the model to adequately reproduce the vertical structure of these properties over the entire domain and over time requires a more thor- ough validation exercise. As mentioned before, this effort is hindered by the lack of Argo data found in this region. Also, those instruments are programed to operate in regions where the bathymetry is greater or equal to $2000 \mathrm{~m}$ depth, limiting the validation processes on coastal waters. Satellite altimetry, another important source of data for open ocean operational modelling, also becomes less applicable because of the errors of the altimeter in coastal areas.

Simulated current velocity displays the typical patterns in its seasonal and mesoscale variability, mostly influenced by the atmospheric circulation that significantly varies throughout the year. Some of the basic circulation patterns and oceanographic features known for the West Iberian coast are reproduced by the model, such as the surface poleward current during winter, upwelling fronts in late spring and summer and associated southward jets, and surface temperature gradients (e.g. Fiuza et al., 1998; Peliz et al., 2002, 2005; Oliveira et al., 2009). However, the lack of field data prevents a thorough validation. HF (high frequency) radar data exists for the Galician region and for the Portuguese Estremadura 


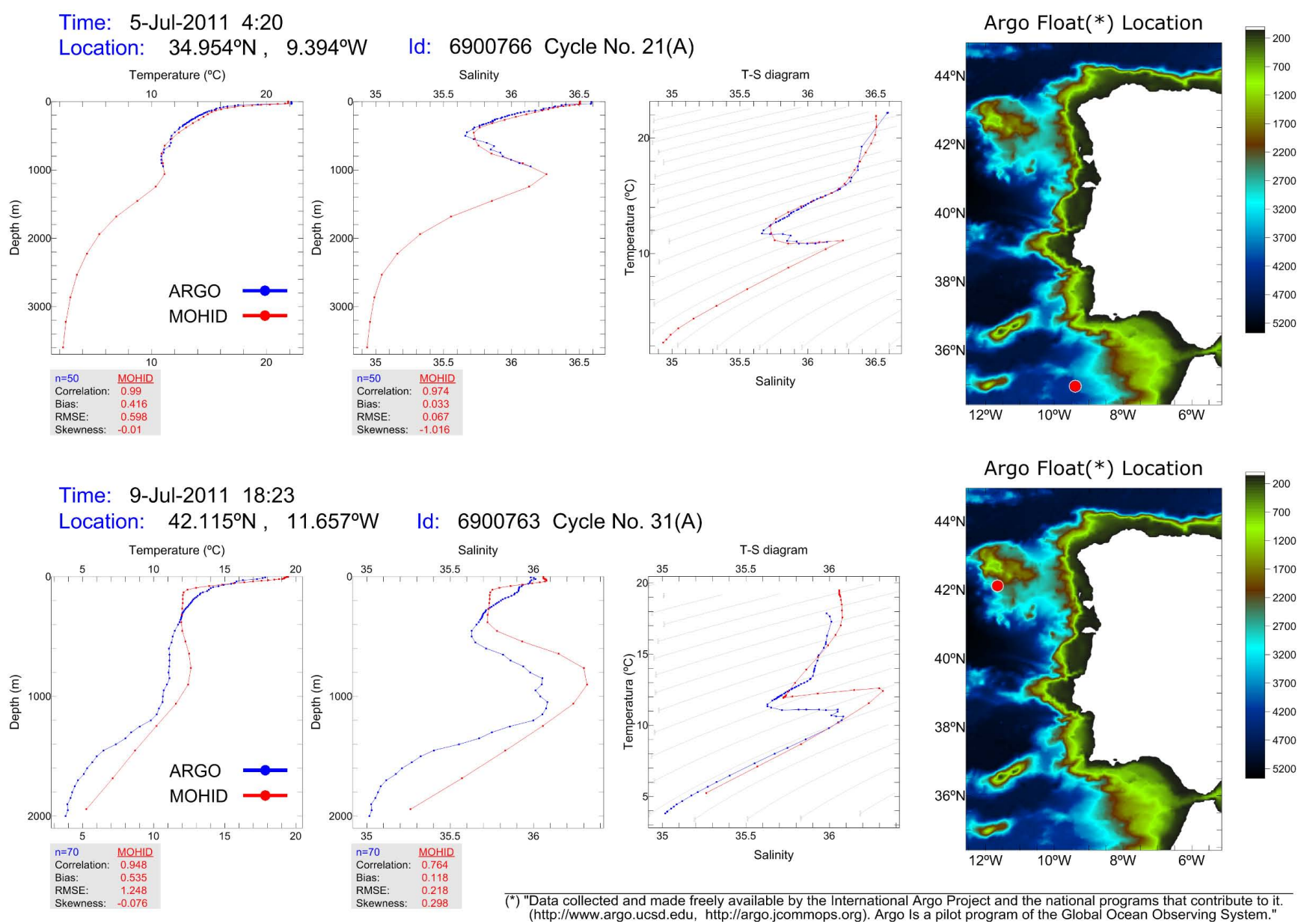

Fig. 11. Simulated temperature and salinity profiles for July 2011 compared with Argo data. The locations of the buoy are represented in the maps by a red circle. Statistical results are also present for each parameter.

region, and it should soon be made available for near future validation of the MOHID-PCOMS.

The permanent eddy present in the south-west region of the map in Figs. 8 and 11 is not present in the baroclinic reference solution and is not present in remote-sensing imagery; it is therefore spurious. This type of trapped spurious eddy near the open boundary may occur due to ill parameterized boundary conditions or due to inconsistent forcing; however, the critical aspect is the quality of the flow over the continental shelf and near the regions of river influence.

\subsection{Applications}

It is intended that operational systems provide the infrastructure to support marine decision making in several areas, and provide relevant information on the dynamics of the marine environment. The specific and complex dynamics of coastal regions present major challenges for the scientific community in terms of numerical forecasting (Zhuang et al., 2011). Also, complex topography and coastlines impose the need for downscaling. The regional forecasting system here pre- sented can address such requirements and provide significant information by being a base for further developments and applications besides the prediction of physical and chemical parameters such as temperature, current fields and salinity.

\subsubsection{Marine safety}

Portugal has the third largest Exclusive Economic Zone (EEZ) in Europe and the 10th largest in the world. Offshore ship traffic is intense because several international waterways cross the Portuguese EEZ such as the Motorway of the Sea of Western Europe, with hundreds of ships circulating daily along the Portuguese coast. This fact confers upon Portugal great responsibility in terms of maritime security, as well as on prevention and response to marine pollution.

Numerical models now have a leading role in operational oceanography applied to safety and pollution response in the ocean because of their predictive potential. Search and rescue operations, and oil, inert (ship debris, or floating containers), and HNS (hazardous and noxious substances) spills risk analysis are the main areas where models are being used 


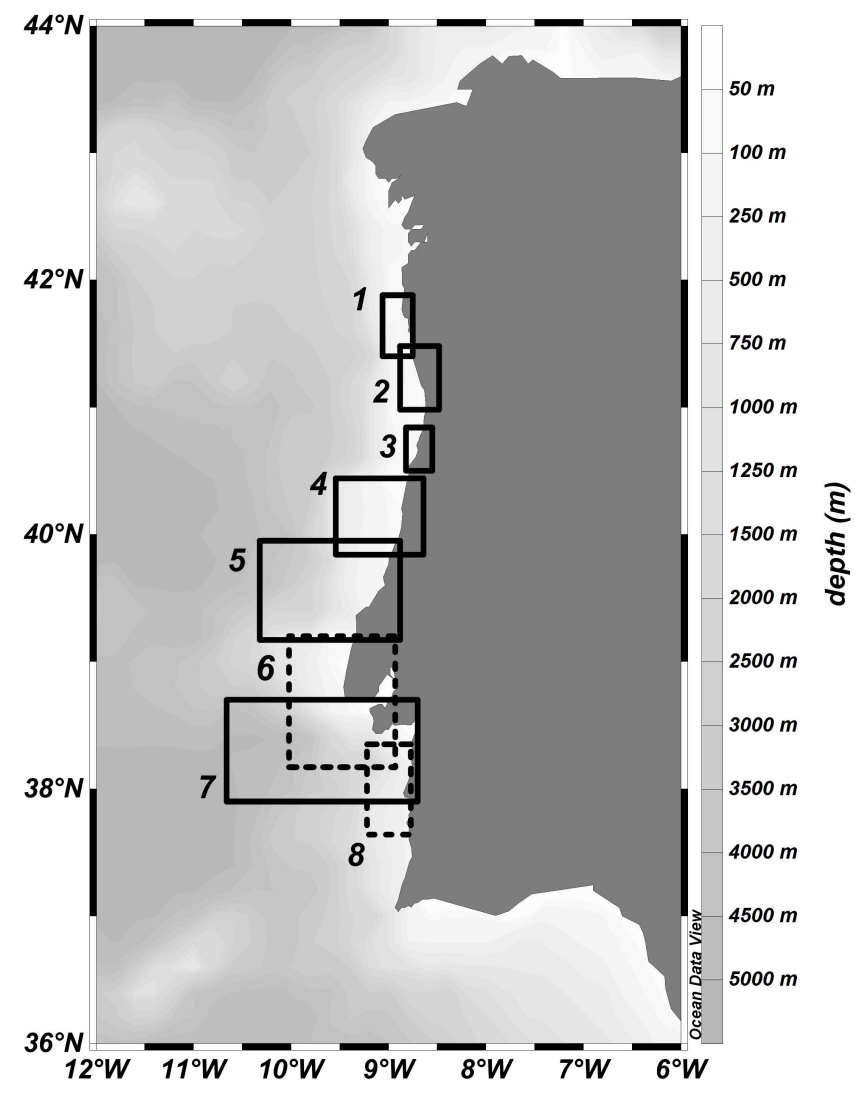

Fig. 12. Smaller scale and local model applications that use the results from MOHID-PCMOS as lateral boundary conditions, either in hindcast or forecast simulations: (1) Viana do Castelo, (2) Leixões, (3) Ria de Aveiro, (4) Mondego estuary and adjacent coastal area, (5) Nazaré canyon, (6) Tagus coastal area, (7) Setúbal canyon, and (8) Sines.

extensively and where their skill is established. The MOHID model has already been used in this context (Santoro et al., 2011). The MOHID-PCOMS results have been used to provide boundary conditions to smaller scale local models applied to pollution prevention and port management at some sites along the Portuguese coast, namely at Viana do Castelo, Leixões and Ria de Aveiro (Fig. 12).

In a similar way, inert, oil and HNS spill forecasting systems are capable of providing information on demand and supporting the marine authorities in case of an emergency, either related with onshore or offshore activities. Oil spill models usually have a 3-D numerical model to calculate the pollutant transport (vertical movement), as well as its weathering (dispersion, evaporation, emulsification, dissolution, beaching and sedimentation). Oil spill operational models have proven to be particularly useful in accidents involving cargo ships (Perivoliotis et al., 2011;González et al., 2008; Breivik et al., 2011), thus becoming widespread during the last decades. Some of these operational systems have developed into Marine Security Decision Support Systems
(DeSS) capable of use and exchange with other systems (e.g. Perivoliotis et al., 2011), thus leading to the creation of the European Decision Support System (EuroDeSS).

The first operational model for West Iberia was developed in the aftermath of the Prestige oil spill on Galician waters using the MOHID model to estimate the extension and patterns of the oil plume dispersion (Carracedo et al., 2006; Balseiro et al., 2003). At this moment a preliminary system is already available for West Iberia, having at its core a model for oil and inert spills already built in MOHID. The system provides estimations about oil spill evolution, the evolution of ship debris, floating containers or man overboard, and uses the MOHID-PCOMS solution for the necessary information about atmospheric and marine conditions.

Additionally, search and rescue events involving human lives (like man overboard situations) are obviously relevant. A number of search and rescue operations take place along the Portuguese coast every year. These are mostly related to fishing boats that get stranded in open waters and to near coast episodes of fishers, swimmers or beach goers who are taken by the sea. According to the Portuguese Statistics Institute (INE), during 2010 there were 7 registered ship foundering episodes, accounting for the loss of 13 human lives and more than 70 injured fishermen (INE, 2011).

Up to this moment there were no operational systems running for the Portuguese coast with search and rescue capabilities. All model applications made in this context have been ad hoc. As such, one of the major applications of the operational model here discussed can be the support of search and rescue operations by providing the major circulation patterns along the Portuguese coast. The vast majority of rescue operations occur close to the coast, meaning that for better estimates a high horizontal resolution is needed to allow the model to assist searches near the shore and in bays. While the MOHID-PCOMS operational model lacks such horizontal resolution, estimates are valuable nevertheless because they can be used as boundary conditions to local high resolution models in a nested configuration.

\subsubsection{Marine resources}

The shelf area of the West Iberia coast is characterized by high biological and hydrodynamic variability, and it is the region where most human contact with the marine systems occurs. Marine resources, such as fishing areas, coastal and estuarine aquaculture units, and bathing areas, are either in this area or under its direct influence. Consequently there is a need for a robust source of hydrodynamic, ecological and water quality data upon timescales useful for decision making regarding the sustainable and safe use of these resources. As an example, operational models, when linked with ecosystem models, can provide useful information to fisheries scientists and decision makers (Robinson and Frid, 2003; Methot Jr., 2009). 


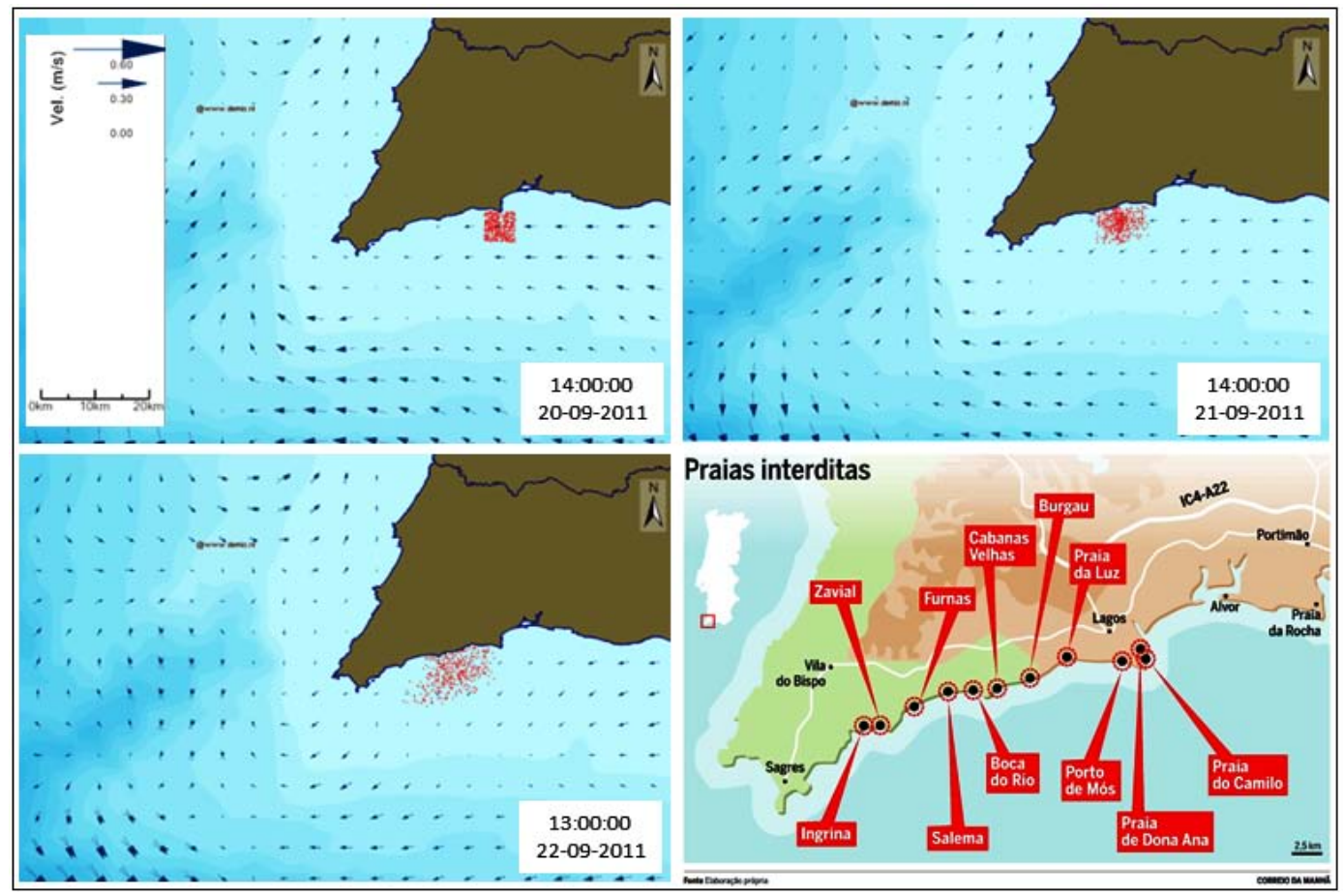

Fig. 13. MOHID-PCOMS forecast for potential impacted areas by the tracking of Ostreopsis $c f$. ovata bloom position. The forecast was used for the decision-making process, leading to the closure of several beaches in a major tourist spots in Portugal (panel in the lower-right side; image retrieved from a national newspaper).

Until now some joint efforts between ocean modellers and the fishing industry have been promoted in the European Atlantic arc, such as the ICES (International Council for the Exploration of the Sea) Working Group Operational Oceanographic Products for Fisheries and the Environment. MOHID-PCOMS has the potential to provide significant information related to fishing resources (Navas et al., 2011; Génio et al., 2008), and its results can be explored in the future in this context. The modular nature of the MOHID model means that it may be used with several modules already available, such the larvae dynamics module (Santos et al., 2005), allowing the possibility for an expansion to the operational capabilities in the future.

By estimating the hydrodynamic regime in the area, this operational modelling platform also has the structure to provide data that can be applied to other marine resources. The straightforward approach of coupling a Lagrangian particletracking model to MOHID-PCOMS gives the possibility of addressing a number of processes related to marine resources. A wide variety of these models linked to hydrodynamic models have been used in order to analyse the dispersion process of specific phenomena. Oil spills, early life stages of fish (eggs and larvae), and algal blooms are among the most common marine phenomena tracked using the Lagrangian approach (e.g. Brickman and Frank, 2000; Huggett et al., 2003; González et al., 2008; Stumpf et al., 2009). These processes are described by a set of particles with different characteristics such as concentration, age or size, and with specific initial values.

Harmful algal blooms (HABs), for example, can have a potential negative impact on marine resources (Davidson et al., 2009; Escalera et al., 2006; Silke et al., 2005; Trainer et al., 2010), therefore posing serious constraints to the sustainable development of coastal areas. HABs are a common occurrence in Portuguese water, both along the coast and offshore (Moita et al., 2003; Vale, 2012; Escalera et al., 2010; Palma et al., 2010). An ocean colouring technique applied to remote-sensing imagery can be used to track these blooms, but this technique is also limited for low-biomass or in subsurface blooms, and it lacks the predictive skills to infer bloom transport beforehand. Operational model, on the other hand, can fill this gap by tracking the transport of the bloom once it is detected. From a management perspective, a major concern is also the ability to predict where a bloom is likely to be transported over a few days from its last known location. Under these circumstances, even a rudimentary forecast system can be useful and could be used as a baseline for future improvements (Velo-Suárez et al., 2010; Wynne et al., 2011).

The usefulness of MOHID-PCOMS to track HAB position has recently been tested in a real situation through the simulation of a nowcast and forecast for potential impacted areas after an Ostreopsis cf. ovata bloom was detected at a beach in the south of Portugal (David et al., 2011). The operational 

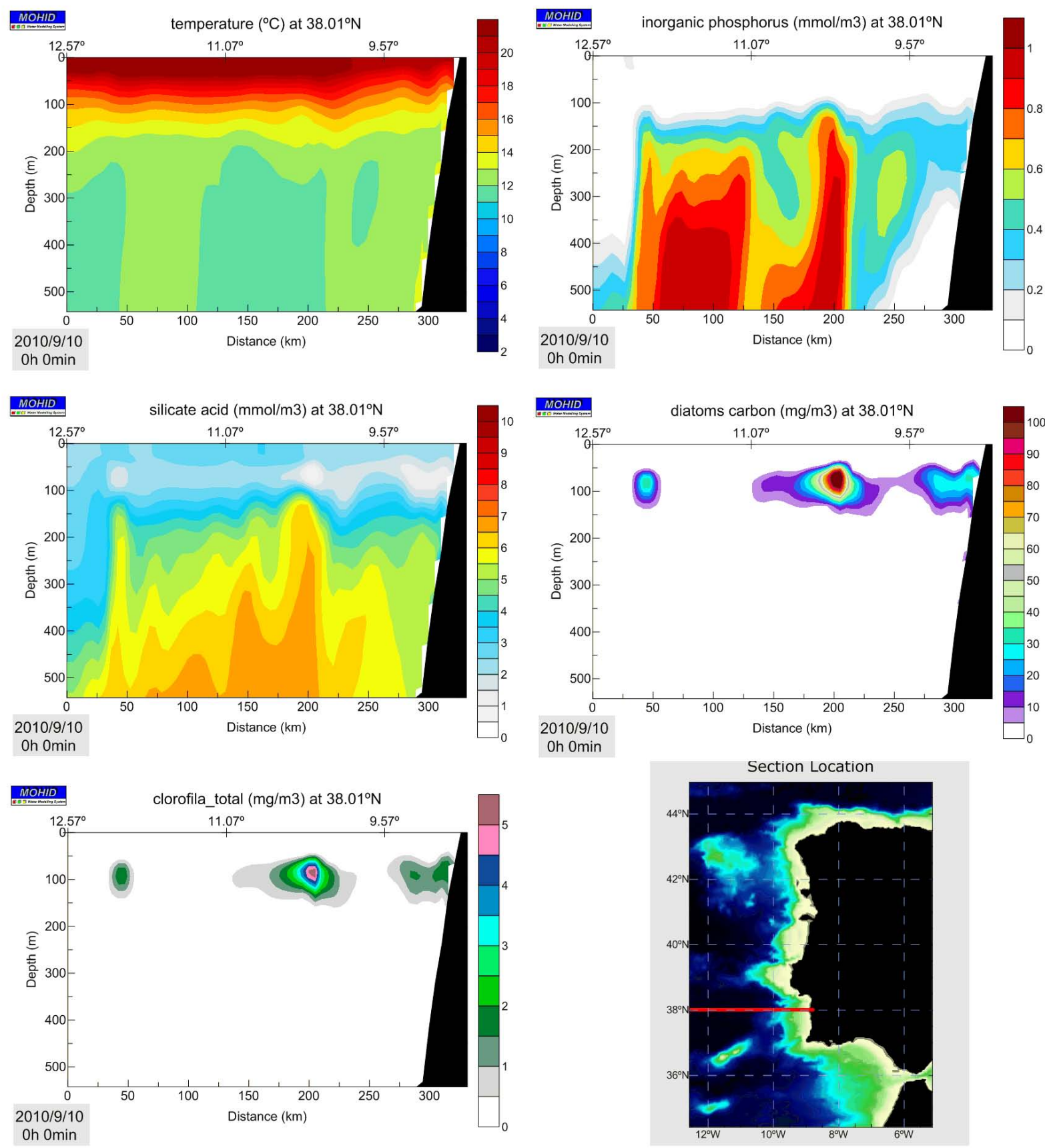

Fig. 14. Zonal section of the south-western coast of Portugal, showing the vertical structure for some properties from the MOHID-PCOMS model coupled with one of the ecological models available in the MOHID. The section location is represented by the red line.

model was used to forecast bloom transport and aggregation/dispersion (Fig. 13) over a 3-day period, in collaboration with the National Institute for Biological Resources (INRBIPIMAR). Model predictions for the potential areas under the influence of the bloom were then used to assist local authorities in the decision-making process of flagging the beaches in those areas. Assuming a risk of the presence of harmful algae, an alert was issued as a safety measure and sev- eral beaches were closed for bathing. The beaches were located westward from the location of emission of the particles (assumed to be the epicenter of the bloom), as depicted in Fig. 13. Passive Lagrangian tracers with beaching capabilities were used, thus no biomass variability was computed. 


\subsubsection{Coastal and marine environment}

One of the most significant contributions from operational models for the study of marine environments is the volume of data that they generate and that can be stored as a synoptic description of the state of the ocean. These data records can either be used to study physical and biogeochemical processes, for example, or as lateral boundary conditions for smaller scale or local models, in hindcast or forecast mode.

There is a growing realisation that the biogeochemical state of our seas cannot be inferred from their physical properties alone (e.g. Blackford et al., 2004), and there is a requirement for explicit operational modelling of the combined physical, chemical and biological systems. In response to this need, coupled oceanic circulation and ecosystem operational models are being used with more frequency (Zalesny and Tamsalu, 2009; Siddorn et al., 2007). The coupled hydrodynamic-ecological operational modelling has been implemented in MOHID-PCOMS with different ecological models.

The potential to simulate biogeochemical processes along the coast and in depth has been tested with an ecological complex model (Mateus, 2012; Mateus et al., 2012), and the preliminary results (Fig. 14) showed that the model is able to reproduce some known ecological features, such as the nutrient depletion in surface layers and the sub-superficial chlorophyll maximum. This coupled modelling approach is the basis to understand the link between physical, chemical and ecological processes occurring in the shelf area. As seen in the example in Fig. 14, the results show the clear relation between thermal stratification, nutrient availability and diatom abundance, highlighting the importance of the physical structure of the ocean in the primary production patterns. The information drawn from this model application can be further used to identify the underlying processes of HAB formation associated with thin layers, such as Dinophysis acuta blooms that are known to occur along the Portuguese coast (Moita et al., 2006). However, the high computational cost of such application hinders its use in an operational way, and currently there is an operational application providing forecast for ecology using a simpler NPZ (nutrient, phytoplankton, zooplankton) model.

The horizontal grid size of MOHID-PCOMS is eddy permitting but may be insufficient to resolve on-shelf mesoscale eddy processes, where a characteristic Rossby radius is expected to be $\sim 3 \mathrm{~km}$. However, the results are used to cascade down to smaller domain applications with higher resolution where needed. Results from MOHID-PCOMS have been used this way in several applications of local models (Fig. 12). Some of these models run in hindcast mode to study local processes, for example the applications to the Ria de Aveiro to simulate water quality processes, and Nazaré and Setubal canyons to study sediment dynamics. Other applications are from local operational systems nested with MOHID-PCOMS, such as the Tagus coastal and estuarine area model and the Sines model. In the first case the solution cascades down to smaller domain models used (1) to study the effect of local streams on microbiologic water quality in beaches, (2) to evaluate the impact of a submarine outfall on the water quality and ecological processes in the surrounding area, and (3) as boundary conditions for the Tagus operational model. In the second situation the local model is used to assess the influence of a thermal plume from a thermoelectric power plant on the coastal dynamics.

\section{Conclusions}

We have presented an operational oceanography system for the West Iberian waters forced by ocean and atmospheric model results provided by local thematic data centres. Potential use cases that deal with problems related to coastal management, marine pollution and safe navigation were addressed, as well as the relevance of the model in providing information to oceanographic studies.

The system is validated by data retrieved from the MyOcean catalogue. The predicted results of the operational system are exported to a web-based data system for realtime dissemination to the public (http://opendap.mohid.com: 8080/thredds/catalog.html). As such, it provides information on the state of the sea, and it provides prediction to all sectors of society: governments, industries, local actors, research and academic groups, and the general public.

The MOHID-PCOMS model has been shown to be an effective modelling tool. The results presented show that this operational tool adequately represents some hydrologic features of the region and their seasonal differences in dynamical processes. The operational system structure is ready to be used in an operational environment where products and services can be provided on request, either for the present day as short-term forecast, or for past events. This is a significant step towards a community model resource with a good potential to become a data source on the state of the ocean and a management tool to support local studies along the West Iberia coast.

Improvements to the model are underway, namely the inclusion of river discharge along the coast and an increase in spatial resolution in near-coast areas where upwelling is frequent. Local models coupled offline are also currently being used, and they will soon run operationally and provide more detailed information on the local state of the sea.

Acknowledgements. This work is partially supported by European FP projects MyOcean (FP7 - SPACE-2007-1) and ASIMUTH (FP7 - SPACE - 261860), and projects EASYCO and ARCOPOL under the INTERREG IV Atlantic Area Program.

Edited by: J. A. Johannessen 


\section{References}

Arakawa, A.: Computational design for long-term numerical integration of the equations of fluid motion: Two-dimensional incompressible flow. Part I, Journal of Computational Physics, 1, 119-143, 1966.

Balseiro, C. F., Carracedo, P., Gómez, B., Leitão, P. C., Montero, P., Naranjo, L., Penabad, E., and Pérez-Muñuzuri, V.: Tracking the Prestige oil spill: An operational experience in simulation at MeteoGalicia, Weather, 58, 452-458, 2003.

Beckmann, A., and Haidvogel, D. B.: Numerical Simulation of Flow around a Tall Isolated Seamount. Part I: Problem Formulation and Model Accuracy, Journal of Physical Oceanography, 23, 1736-1753, 1993.

Bell, M. J., Lefèbvre, M., Le Traon, P.-Y., Smith, N., and WilmerBecker, K.: GODAE: the global Ocean data assimilation experiment, Oceanography, 22, 14-21, 2009.

Blackford, J. C., Allen, J. I., and Gilbert, F. J.: Ecosystem dynamics at six contrasting sites: a generic modelling study, Journal of Marine Systems, 52, 191-215, DOI 10.1016/j.jmarsys.2004.02.004, 2004.

Blumberg, A. F., and Kantha, L.: Open Boundary Condition for Circulation Models, Journal of Hydraulic Engineering, 111, 237255, 1985.

Breivik, Ø., Allen, A. A., Maisondieu, C., and Roth, J. C.: Windinduced drift of objects at sea: The leeway field method, Applied Ocean Research, 33, 100-109, 10.1016/j.apor.2011.01.005, 2011.

Brickman, D., and Frank, T.: Modelling the dispersal and mortality of Browns bank egg and larval haddock (Melanogrammus aeglefinus), Can. J. Fish. Aquat. Sci., 57, 2519-2535, 2000.

Bryan, K.: A Numerical Method for the Study of the Circulation of the World Ocean, Journal of Computational Physics, 135 154169, 1997.

Burchard, H.: Applied Turbulence Modelling in Marine Waters, no. 100 in Lecture Notes in Earth Sciences, Springer, 2002.

Cailleau, S., Chanut, J., Levier, B., Maraldi, C., and Reffray, G.: The new regional generation of Mercator Ocean system in the Iberian Biscay Irish (IBI) area, Mercator Quarterly Newsletter, 34, 5-15, 2010.

Canuto, V. M. V., Howard, A., Cheng, Y., and Dubovikov, M. S. M.: Ocean Turbulence. Part I: One-Point Closure Model-Momentum and Heat Vertical Diffusivities, Journal of Physical Oceanography, 31, 1413-1426, 2001.

Carracedo, P., Torres-López, S., Barreiro, M., Montero, P., Balseiro, C. F., Penabad, E., Leitao, P. C., and Pérez-Muñuzuri, V.: Improvement of pollutant drift forecast system applied to the Prestige oil spills in Galicia Coast (NW of Spain): development of an operational system, Marine Pollution Bulletin, 53, 350-360, 2006.

David, H., Moita, M. T., Laza-Martínez, A., Silva, A., Mateus, M., de Pablo, H., and Orive, E.: First bloom of Ostreopsis cf. ovata in the continental Portuguese coast, Harmful Algae News 45, 2011.

Davidson, K., Miller, P. I., Wilding, T., Shutler, J., Bresnan, E., Kennington, K., and Swan, S.: A large and prolonged bloom of Karenia mikimotoi in Scottish waters in 2006, Harmful Algae, 8, 349361, 2009.

De Mey, P., and Proctor, R.: Assessing the value of GODAE products in coastal and shelf seas, Ocean Dynamics, 59, 1-2, 2009.
Delhez, E., and Deleersnijder, E.: Overshootings and spurious oscillations caused by biharmonic mixing, Ocean Modelling, 17, 183-198, 2007.

Drillet, Y.: Meddies in the Mercator North Atlantic and Mediterranean Sea eddy-resolving model, Journal of Geophysical Research, 110, 1-16, 2005.

Escalera, L., Reguera, B., Pazos, Y., Morono, A., and Cabanas, J. M.: Are different species of Dinophysis selected by climatological conditions?, Afr J Mar Sci, 28, 283-288, 2006.

Escalera, L., Reguera, B., Moita, T., Pazos, Y., Cerejo, M., Cabanas, J. M., and Ruiz-Villarreal, M.: Bloom dynamics of Dinophysis acuta in an upwelling system: In situ growth versus transport, Harmful Algae, 9, 312-322, 10.1016/j.hal.2009.12.002, 2010.

Fiuza, A. F. G., Hamann, M., Ambar, I., del Rio, G. D., Gonzalez, N., and Cabanas, J. M.: Water masses and their circulation off western Iberia during May 1993, Deep-Sea Res Pt I, 45, 11271160, 1998.

Flather, R. A.: A tidal model of the north-west European continental shelf, Memoires de la Societe Royale des Sciences de Liege, 6, 141-164, 1976.

Fofonoff, N. P., and Millard, R. C.: Algorithms for computation of fundamental properties of seawater, Unesco technical papers in marine science, 44, 1983.

Génio, L., Sousa, A., Vaz, N., Dias, J. M., and Barroso, C.: Effect of low salinity on the survival of recently hatched veliger of Nassarius reticulatus (L.) in estuarine habitats: A case study of Ria de Aveiro, Journal of Sea Research, 59, 133-143, 10.1016/j.seares.2007.09.001, 2008.

González, M., Ferrer, L., Uriarte, A., Urtizberea, A., and Caballero, A.: Operational Oceanography System applied to the Prestige oil-spillage event, Journal of Marine Systems, 72, 178188, 10.1016/j.jmarsys.2007.07.005, 2008.

Holt, J. T., and James, I. D.: A simulation of the southern North Sea in comparison with measurements from the North Sea project, Part 1, Temperature, Continental Shelf Research, 19, 1087-1112, 1999.

Huggett, J., Fréon, P., Mullon, C., and Penven, P.: Modelling the transport success of anchovy Engraulis encrasicolus eggs and larvae in the southern Benguela: the effect of spatio-temporal spawning patterns, Mar. Ecol. Prog. Ser., 250, 247-262, 2003.

INE: Estatísticas da Pesca 2010, Instituto Nacional de Estatística, Lisboa, Portugal, 101, 2011.

Kordzadze, A. A. and Demetrashvili, D. I.: Operational forecast of hydrophysical fields in the Georgian Black Sea coastal zone within the ECOOP, Ocean Sci., 7, 793-803, doi:10.5194/os-7793-2011, 2011.

Korotaev, G. K., Oguz, T., Dorofeyev, V. L., Demyshev, S. G., Kubryakov, A. I., and Ratner, Yu. B.: Development of Black Sea nowcasting and forecasting system, Ocean Sci., 7, 629-649, doi:10.5194/os-7-629-2011, 2011.

Le Traon, P.-Y., Larnicol, G., Guinehut, S., Pouliquen, S., Bentamy, A., Roemmich, D., Donlon, C., Roquet, H., Jacobs, G., Griffin, D., Bonjean, F., Hoepffner, N., and Breivik, L. A.: Data assembly and processing for operational oceanography: 10 years of achievements, Oceanography, 22, 56-69, doi:10.5670/oceanog.2009.66., 2009.

Leendertse, J. J.: Aspects of a Computational Model for Longperiod Water-wave Propagation, Rand Corporation for the United States Air Force Project Rand, 1967. 
Lefèvre, F., Lyard, F. H., Le Provost, C., and Schrama, E. J. O.: FES99: A Global Tide Finite Element Solution Assimilating Tide Gauge and Altimetric Information, J. Atmos. Ocean. Tech., 19, 1345-1356, doi:10.1175/15200426(2002)019<1345:fagtfe > 2.0.co;2, 2002.

Leitão, P., Coelho, H., Santos, A., and Neves, R.: Modelling the main features of the Algarve coastal circulation during July 2004: A downscaling approach, J. Atmos. Ocean Sci., 10, 421-462, 2005 , http://www.ocean-sci.net/10/421/2005/.

Lyard, F., Lefevre, F., Letellier, T., and Francis, O.: Modelling the global ocean tides: modern insights from FES2004, Ocean Dynam., 56, 394-415, doi:10.1007/s10236-006-0086-x, 2006.

Martins, F., Neves, R., and Leitão, P. C.: A three-dimensional hydrodynamic model with generic vertical coordinate, Hydroinformatics, 98, 1403-1410, 1998.

Martins, F., Leitão, P., Silva, A., and Neves, R.: 3D modelling in the Sado estuary using a new generic vertical discretization approach, Ocean. Ac., 24, S51-S62, 2001.

Martinsen, E. A. and Engedahl, H.: Implementation and testing of a lateral boundary scheme as an open boundary condition in a barotropic ocean model, Coast. Eng., 11, 603-627, 1987.

Mateus, M.: A process-oriented model of pelagic biogeochemistry for marine systems. Part I: Model description, J. Mar. Syst., 94, S78-S89, doi:10.1016/j.jmarsys.2011.11.008, 2012.

Mateus, M., Leitão, P. C., de Pablo, H., and Neves, R.: Is it relevant to explicitly parameterize chlorophyll synthesis in marine ecological models?, J. Mar. Syst., 94, S23-S33, doi:10.1016/j.jmarsys.2011.11.007, 2012.

Methot Jr., R. D.: Stock Assessment: Operational Models in Support of Fisheries Management, in: The Future of Fisheries Science in North America, edited by: Beamish, R. J. and Rothschild, B. J., Fish Fish. Ser., Springer Science + Business Media B.V., 137-165, 2009.

Moita, M. T., Oliveira, P. B., Mendes, J. C., and Palma, A. S.: Distribution of chlorophyll a and Gymnodinium catenatum associated with coastal upwelling plumes off central Portugal, Acta. Oecologia, 24, 125-132, 2003.

Moita, M. T., Sobrinho-Goncalves, L., Oliveira, P. B., Palma, S., and Falcao, M.: A bloom of Dinophysis acuta in a thin layer off north-west Portugal, Afr. J. Mar. Sci., 28, 265-269, 2006.

Navas, J. M., Telfer, T. C., and Ross, L. G.: Application of 3D hydrodynamic and particle tracking models for better environmental management of finfish culture, Cont. Shelf Res., 31, 675-684, doi:10.1016/j.csr.2011.01.001, 2011.

Oddo, P. and Guarnieri, A.: A study of the hydrographic conditions in the Adriatic Sea from numerical modelling and direct observations (2000-2008), Ocean Sci., 7, 549-567, doi:10.5194/os-7549-2011, 2011.

Oliveira, P. B., Nolasco, R., Dubert, J., Moita, T., and Peliz, A.: Surface temperature, chlorophyll and advection patterns during a summer upwelling event off central Portugal, Cont. Shelf Res., 29, 759-774, doi:10.1016/j.csr.2008.08.004, 2009.

Palma, S., Mouriño, H., Silva, A., Barão, M. I., and Moita, M. T.: Can Pseudo-nitzschia blooms be modeled by coastal upwelling in Lisbon Bay?, Harmful Algae, 9, 294-303, doi:10.1016/j.hal.2009.11.006, 2010.

Peliz, A., Rosa, T. L., Santos, A. M. P., and Pissarra, J. L.: Fronts, jets, and counter-flows in the Western Iberian upwelling system,
J. Mar. Syst., 35, 61-77, 2002.

Peliz, A., Dubert, J., Santos, A. M. P., Oliveira, P. B., and Le Cann, B.: Winter upper ocean circulation in the Western Iberian Basin Fronts, Eddies and Poleward Flows: an overview, Deep-Sea Res Pt. I, 52, 621-646, doi:10.1016/j.dsar.2004.11.005, 2005.

Perivoliotis, L., Krokos, G., Nittis, K., and Korres, G.: The Aegean sea marine security decision support system, Ocean Sci., 7, 671683, doi:10.5194/os-7-671-2011, 2011.

Riflet, G., Juliano, M., Fernandes, L. L., Leitão, P. C., and Neves, R.: Operational Ocean forecasting of the Portuguese waters, Mercator Quarterly Newsletter, 30, 20-32, 2008.

Robinson, L. A. and Frid, C. L. J.: Dynamic ecosystem models and the evaluation of ecosystem effects of fishing: can we make meaningful predictions?, Aquat. Conserv., 13, 5-20, doi:10.1002/Aqc.506, 2003.

Ruiz-Villarreal, M., Bolding, K., Burchard, H., and Demirov, E.: Coupling of the GOTM turbulence module to some threedimensional ocean models, in: Marine Turbulence: Theories, Observations, and Models. Results of the CARTUM Project, edited by: Baumert, H. Z., Simpson, J. H., and Sundermann, J., Cambridge University Press, 225-237, 2005.

Santoro, P., Fernandez, M., Fossati, M., Cazes, G., Terra, R., and Piedra-Cueva, I.: Pre-operational forecasting of sea level height for the Rio de la Plata, Appl. Math. Model, 35, 2462-2478, doi:10.1016/j.apm.2010.11.065, 2011.

Santos, A. J. P., Nogueira, J., and Martins, H.: Survival of sardine larvae off the Atlantic Portuguese coast: a preliminary numerical study, Ices J. Mar. Sci., 62, 634-644, doi:10.1016/j.icesjms.2005.02.007, 2005.

Siddorn, J. R., Allen, J. I., Blackford, J. C., Gilbert, F. J., Holt, J. T., Holt, M. W., Osborne, J. P., Proctor, R., and Mills, D. K.: Modelling the hydrodynamics and ecosystem of the North-West European continental shelf for operational oceanography, J. Mar. Syst., 65, 417-429, doi:10.1016/j.jmarsys.2006.01.018, 2007.

Silke, J., O'Beirn, F., and Cronin, M.: Karenia: an exceptional dinoflagellate bloom in western Irish waters, summer 2005, Marine Institute, Galway, Ireland, 44, 2005.

Sousa, T.: Previsão Meteorológica em Portugal Continental utilizando o modelo operacional e de investigação MM5, Instituto Superior Técnico, Lisbon Technical University, 2002.

Stanev, E. V., Schulz-Stellenfleth, J., Staneva, J., Grayek, S., Seemann, J., and Petersen, W.: Coastal observing and forecasting system for the German Bight - estimates of hydrophysical states, Ocean Sci., 7, 569-583, doi:10.5194/os-7-569-2011, 2011.

Stumpf, R. P., Tomlinson, M. C., Calkins, J. A., Kirkpatrick, B., Fisher, K., Nierenberg, K., Currier, R., and Wynne, T. T.: Skill assessment for an operational algal bloom forecast system, J. Mar. Syst., 76, 151-161, doi:10.1016/j.jmarsys.2008.05.016, 2009.

Trainer, V. L., Pitcher, G. C., Reguera, B., and Smayda, T. J.: The distribution and impacts of harmful algal bloom species in eastern boundary upwelling systems, Prog. Oceanogr., 85, 33-52, doi:10.1016/j.pocean.2010.02.003, 2010.

Vale, P.: Two simple models for accounting mussel contamination with diarrhoetic shellfish poisoning toxins at Aveiro lagoon: Control by rainfall and atmospheric forcing, Estuarine, Coast. Shelf Sci., 98, 94-100, doi:10.1016/j.ecss.2011.12.007, 2012.

Varela, M., Álvarez-Ossorio, M. T., Bode, A., Prego, R., Bernárdez, P., and Garcia-Soto, C.: The effects of a winter upwelling on biogeochemical and planktonic components in an area close to the 
Galician Upwelling Core: The Sound of Corcubión (NW Spain), J. Sea Res., 64, 260-272, doi:10.1016/j.seares.2010.03.004, 2010.

Velo-Suárez, L., Reguera, B., González-Gil, S., Lunven, M., Lazure, P., Nézan, E., and Gentien, P.: Application of a 3D Lagrangian model to explain the decline of a Dinophysis acuminata bloom in the Bay of Biscay, J. Mar. Syst., 83, 242-252, 2010.

Wynne, T. T., Stumpf, R. P., Tomlinson, M. C., Schwab, D. J., Watabayashi, G. Y., and Christensen, J. D.: Estimating cyanobacterial bloom transport by coupling remotely sensed imagery and a hydrodynamic model, Ecol. Appl., 21, 2709-2721, 2011.
Zalesny, V. B. and Tamsalu, R.: High-resolution modeling of a marine ecosystem using the FRESCO hydroecological model. Izvestiya, Atmos. Ocean. Phys., 45, 108-122, 2009.

Zhuang, S. Y., Fu, W. W., and She, J.: A pre-operational three Dimensional variational data assimilation system in the North/Baltic Sea, Ocean Sci., 7, 771-781, doi:10.5194/os-7-7712011, 2011. 